IZA DP No. 4242

\title{
Forecasting with Spatial Panel Data
}

Badi H. Baltagi

Georges Bresson

Alain Pirotte

June 2009 


\title{
Forecasting with Spatial Panel Data
}

\author{
Badi H. Baltagi \\ Syracuse University \\ and IZA
}

Georges Bresson

ERMES (CNRS), Université Panthéon-Assas Paris II

Alain Pirotte

ERMES (CNRS), Université Panthéon-Assas Paris II

and INRETS-DEST

\section{Discussion Paper No. 4242 \\ June 2009}

IZA

P.O. Box 7240

53072 Bonn

Germany

Phone: $+49-228-3894-0$

Fax: +49-228-3894-180

E-mail: iza@iza.org

\begin{abstract}
Any opinions expressed here are those of the author(s) and not those of IZA. Research published in this series may include views on policy, but the institute itself takes no institutional policy positions.

The Institute for the Study of Labor (IZA) in Bonn is a local and virtual international research center and a place of communication between science, politics and business. IZA is an independent nonprofit organization supported by Deutsche Post Foundation. The center is associated with the University of Bonn and offers a stimulating research environment through its international network, workshops and conferences, data service, project support, research visits and doctoral program. IZA engages in (i) original and internationally competitive research in all fields of labor economics, (ii) development of policy concepts, and (iii) dissemination of research results and concepts to the interested public.
\end{abstract}

IZA Discussion Papers often represent preliminary work and are circulated to encourage discussion. Citation of such a paper should account for its provisional character. A revised version may be available directly from the author. 


\section{ABSTRACT}

\section{Forecasting with Spatial Panel Data*}

This paper compares various forecasts using panel data with spatial error correlation. The true data generating process is assumed to be a simple error component regression model with spatial remainder disturbances of the autoregressive or moving average type. The best linear unbiased predictor is compared with other forecasts ignoring spatial correlation, or ignoring heterogeneity due to the individual effects, using Monte Carlo experiments. In addition, we check the performance of these forecasts under misspecification of the spatial error process, various spatial weight matrices, and heterogeneous rather than homogeneous panel data models.

JEL Classification: $\quad$ C33

Keywords: forecasting, BLUP, panel data, spatial dependence, heterogeneity

Corresponding author:

Badi H. Baltagi

Department of Economics and Center for Policy Research

426 Eggers Hall

Syracuse University

Syracuse, NY 13244-1020

USA

E-mail: bbaltagi@maxwell.syr.edu

* This paper was presented at a conference in honor of Phoebus Dhrymes in Paphos, Cyprus, June 13, 2007. Also, at the 14th International Conference on Panel Data at the Wang Yanan Institute for Studies in Economics (WISE), Xiamen University, China, July 16-18, 2007, and the 63rd European Meeting of the Econometric Society (ESEM) held at the University of Bocconi in Milan, Italy, August 27-31, 2008. 


\section{Introduction}

The literature on forecasting is rich with time series applications, but this is not the case for spatial panel data applications. Exceptions are Baltagi and $\mathrm{Li}(2004,2006)$ with applications to forecasting sales of cigarettes and liquor per capita for U.S. states over time. ${ }^{1}$ Best linear unbiased prediction (BLUP) in panel data using an error component model have been considered by Taub (1979), Baltagi and Li (1992), and Baillie and Baltagi (1999) to mention a few. Applications include Baltagi and Griffin (1997), Hsiao and Tahmiscioglu (1997), Schmalensee, Stoker and Judson (1998), Baltagi, Griffin and Xiong (2000), Hoogstrate, Palm and Pfann (2000), Baltagi, Bresson and Pirotte (2002, 2004), Frees and Miller (2004), Rapach and Wohar (2004), and Brucker and Siliverstovs (2006), see Baltagi (2008) for a recent survey. However, these panel forecasting applications do not deal with spatial dependence across the panel units. Spatial dependence models - popular in regional science and urban economics - deal with spatial interaction and spatial heterogeneity (see Anselin (1988) and Anselin and Bera (1998)). The structure of the dependence can be related to location and distance, both in a geographic space as well as a more general economic or social network space. Some commonly used spatial error processes include the spatial autoregressive (SAR) and the spatial moving average (SMA) error processes. Two different variants of these models for spatial panels are considered, one discussed in Anselin (1988) and another in Kapoor, Kelejian and Prucha (2007) and Fingleton (2007). The best linear unbiased predictors for the Anselin type model was derived by Baltagi and Li (2004). This paper derives the best linear unbiased predictors for the Kapoor, Kelejian and Prucha (2007) and Fingleton (2007) variants. More importantly, it compares the performance of sixteen various forecasts of the spatial panel data using Monte Carlo experiments. These include homogeneous as well as heterogeneous estimators of the spatial panel model and their corresponding forecasts. The true data generating process is assumed to be a simple error component regression model with spatial remainder disturbances of the autoregressive or moving average

\footnotetext{
${ }^{1}$ In order to explain how spatial autocorrelation may arise in the demand for cigarettes, we note that cigarette prices vary among states primarily due to variation in state taxes on cigarettes. Border effect purchases not included in the cigarette demand equation can cause spatial autocorrelation among the disturbances. In forecasting sales of cigarettes, the spatial autocorrelation due to neighboring states and the individual heterogeneity across states is taken explicitly into account.
} 
type. The best linear unbiased predictor is compared with other forecasts ignoring spatial correlation, or ignoring heterogeneity due to the individual effects. In addition, we check the performance of these forecasts under misspecification of the spatial error process, different spatial weight matrices, and various sample sizes. Section 2 introduces the error component model with spatially autocorrelated residuals of the SAR and SMA type. Section 3 describes the forecasts using the estimators considered in Section 2, while Section 4 gives the Monte Carlo design. Section 5 reports the results of the Monte Carlo simulations and Section 6 gives our summary and conclusion.

\section{The Error Component Model with Spatially Autocorrelated Residuals}

Consider a linear panel data regression model:

$$
y_{i t}=X_{i t} \beta+\varepsilon_{i t}, i=1, \ldots, N ; t=1, \ldots, T
$$

where the disturbance term follows an error component model with spatially autocorrelated residuals. The disturbance vector for time $t$ is given by:

$$
\varepsilon_{t}=\mu+\phi_{t}
$$

where $\varepsilon_{t}=\left(\varepsilon_{1 t}, \ldots, \varepsilon_{N t}\right)^{\prime}, \mu=\left(\mu_{1}, \ldots, \mu_{N}\right)^{\prime}$ denotes the vector of specific effects assumed to be iid $\left(0, \sigma_{\mu}^{2}\right)$ and $\phi_{t}=\left(\phi_{1 t}, \ldots, \phi_{N t}\right)^{\prime}$ are the remainder disturbances which are independent of $\mu$. We let the $\phi_{t}$ 's follow a spatial autoregressive (SAR) or a spatial moving average (SMA) error model. The SAR process is known to transmit the shocks globally while the SMA process transmits these shocks locally, see Anselin, Le Gallo and Jayet (2008).

The SAR specification for the $(N \times 1)$ error vector $\phi_{t}$ at time $t$ can be expressed as:

$$
\phi_{t}=\rho W_{N} \phi_{t}+v_{t}=\left(I_{N}-\rho W_{N}\right)^{-1} v_{t}=B_{N}^{-1} v_{t}
$$

where $W_{N}$ is an $(N \times N)$ known spatial weights matrix ${ }^{2}, \rho$ is the spatial autoregressive parameter and $v_{t}$ is an $(N \times 1)$ error vector assumed to be dis-

\footnotetext{
${ }^{2}$ In the simplest case, the weights matrix is binary, with $w_{i j}=1$ when $i$ and $j$ are neighbors and $w_{i j}=0$ when they are not. By convention, diagonal elements are null: $w_{i i}=0$ and the weights are almost always standardized such that the elements of each row sum to 1 .
} 
tributed independently across cross-sectional dimension with constant variance $\sigma_{v}^{2} I_{N} . B_{N}=\left(I_{N}-\rho W_{N}\right)$ and is assumed to be non-singular. The error covariance matrix for the cross-section at time $t$ becomes:

$$
\Omega_{t}=E\left[\varepsilon_{t} \varepsilon_{t}^{\prime}\right]=\sigma_{\mu}^{2} I_{N}+\sigma_{v}^{2}\left(B_{N}^{\prime} B_{N}\right)^{-1}
$$

For the full $(N T \times 1)$ vector of disturbances:

$$
\varepsilon=\left(\iota_{T} \otimes I_{N}\right) \mu+\left(I_{T} \otimes B_{N}^{-1}\right) v
$$

the corresponding $(N T \times N T)$ covariance matrix is given by:

$$
\Omega=\sigma_{\mu}^{2}\left(J_{T} \otimes I_{N}\right)+\sigma_{v}^{2}\left[I_{T} \otimes\left(B_{N}^{\prime} B_{N}\right)^{-1}\right]
$$

where $\iota_{T}$ is a $(T \times 1)$ vector of ones and $J_{T}=\iota_{T} \iota_{T}^{\prime}$ is a $(T \times T)$ matrix of ones.

The spatial moving average $(\mathrm{SMA})$ specification for the $(N \times 1)$ error vector $\phi_{t}$ at time $t$ can be expressed as:

$$
\phi_{t}=\lambda W_{N} v_{t}+v_{t}=\left(I_{N}+\lambda W_{N}\right) v_{t}=D_{N} v_{t}
$$

where $D_{N}=\left(I_{N}+\lambda W_{N}\right)$. The error covariance matrix for the cross-section at time $t$ becomes:

$$
\Omega_{t}=E\left[\varepsilon_{t} \varepsilon_{t}^{\prime}\right]=\sigma_{\mu}^{2} I_{N}+\sigma_{v}^{2}\left(D_{N} D_{N}^{\prime}\right)
$$

For the full $(N T \times 1)$ vector of disturbances:

$$
\varepsilon=\left(\iota_{T} \otimes I_{N}\right) \mu+\left(I_{T} \otimes D_{N}\right) v
$$

the corresponding $(N T \times N T)$ covariance matrix is given by:

$$
\Omega=\sigma_{\mu}^{2}\left(J_{T} \otimes I_{N}\right)+\sigma_{v}^{2}\left[I_{T} \otimes\left(D_{N} D_{N}^{\prime}\right)\right]
$$

MLE under normality of the disturbances using these error component models with spatial autocorrelation have been derived by Anselin (1988). The log-likelihood is given by:

$$
L \propto-\frac{N T}{2} \ln \left(2 \pi \sigma_{v}^{2}\right)-\frac{1}{2} \ln |\Sigma|-\frac{1}{2 \sigma_{v}^{2}} \varepsilon^{\prime} \Sigma^{-1} \varepsilon
$$


where

$$
\begin{aligned}
\varepsilon & =y-X \beta, \Omega=\sigma_{v}^{2} \Sigma \\
\Sigma & =\left\{\begin{array}{lll}
\left(J_{T} \otimes \theta I_{N}\right)+\left[I_{T} \otimes\left(B_{N}^{\prime} B_{N}\right)^{-1}\right] & \text { for } & \text { SAR } \\
\left(J_{T} \otimes \theta I_{N}\right)+\left[I_{T} \otimes\left(D_{N} D_{N}^{\prime}\right)\right] & \text { for SMA }
\end{array}\right. \\
\text { with } \theta & =\sigma_{\mu}^{2} / \sigma_{v}^{2} .
\end{aligned}
$$

Regression models containing spatially correlated disturbance terms based on the SAR or SMA models are typically estimated using MLE, where the likelihood function corresponds to the normal distribution. However, this can be computationally demanding for large $N$. Kelejian and Prucha (1999) suggested a generalized moments (GM) estimation method for the SAR model in a cross-section setting, and Fingleton (2007) extended this generalized moments estimator to the SMA model. Kapoor, Kelejian and Prucha (2007) generalized this GM procedure from cross-section to panel data and derived its large sample properties when $T$ is fixed and $N \rightarrow \infty$. However, their SAR random effects model (SAR-RE) differs from that described in (2) which we will call (RE-SAR). In fact, in their specification, the disturbance term $\varepsilon_{t}$ itself follows a SAR process and the remainder term follows an error component structure. This allows the individual effects, i.e., the $\mu$ 's themselves to be spatially correlated but with the same $\rho$. In particular, the disturbance vector for time $t$ is given by:

$$
\varepsilon_{t}=\rho W_{N} \varepsilon_{t}+u_{t}
$$

where $u_{t}$ follows an error component structure :

$$
u_{t}=\mu+v_{t}
$$

The SAR-RE specification for the $(N \times 1)$ error vector $\varepsilon_{t}$ at time $t$ can be expressed as:

$$
\varepsilon_{t}=\left(I_{N}-\rho W_{N}\right)^{-1} u_{t}=B_{N}^{-1} u_{t}
$$

where $B_{N}=\left(I_{N}-\rho W_{N}\right)$. For the full $(N T \times 1)$ vector of disturbances:

$$
\varepsilon=\left(\iota_{T} \otimes B_{N}^{-1}\right) \mu+\left(I_{T} \otimes B_{N}^{-1}\right) v
$$

and the corresponding $(N T \times N T)$ covariance matrix is given by:

$$
\Omega=\sigma_{\mu}^{2}\left(J_{T} \otimes\left(B_{N}^{\prime} B_{N}\right)^{-1}\right)+\sigma_{v}^{2}\left[I_{T} \otimes\left(B_{N}^{\prime} B_{N}\right)^{-1}\right]
$$


Kapoor, et al. (2007) proposed three generalized moments (GM) estimators of $\rho, \sigma_{v}^{2}$ and $\sigma_{1}^{2}\left(=\sigma_{v}^{2}+T \sigma_{\mu}^{2}\right)$ based on the following six moment conditions:

$$
E\left[\begin{array}{c}
\frac{1}{N(T-1)} u_{N}^{\prime} Q_{0, N} u_{N} \\
\frac{1}{N(T-1)} \bar{u}_{N}^{\prime} Q_{0, N} \bar{u}_{N} \\
\frac{1}{N(T-1)} \bar{u}_{N}^{\prime} Q_{0, N} u_{N} \\
\frac{1}{N} u_{N}^{\prime} Q_{1, N} u_{N} \\
\frac{1}{N} \bar{u}_{N}^{\prime} Q_{1, N} \bar{u}_{N} \\
\frac{1}{N} \bar{u}_{N}^{\prime} Q_{1, N} u_{N}
\end{array}\right]=\left[\begin{array}{c}
\sigma_{v}^{2} \\
\sigma_{v}^{2} \frac{1}{N} \operatorname{tr}\left(W_{N}^{\prime} W_{N}\right) \\
0 \\
\sigma_{1}^{2} \\
\sigma_{1}^{2} \frac{1}{N} \operatorname{tr}\left(W_{N}^{\prime} W_{N}\right) \\
0
\end{array}\right]
$$

where

$$
\begin{aligned}
u_{N} & =\varepsilon_{N}-\rho \bar{\varepsilon}_{N} \\
\bar{u}_{N} & =\bar{\varepsilon}_{N}-\rho \overline{\bar{\varepsilon}}_{N} \\
\bar{\varepsilon}_{N} & =\left(I_{T} \otimes W_{N}\right) \varepsilon_{N} \\
\bar{\varepsilon}_{N} & =\left(I_{T} \otimes W_{N}\right) \bar{\varepsilon}_{N} \\
Q_{0, N} & =\left(I_{T}-\frac{J_{T}}{T}\right) \otimes I_{N} \\
Q_{1, N} & =\frac{J_{T}}{T} \otimes I_{N}
\end{aligned}
$$

Under the random effects specification considered, the OLS estimator of $\beta$ is consistent. Using $\widehat{\beta}_{O L S}$ one gets a consistent estimator of the disturbances $\widehat{\varepsilon}=y-X \widehat{\beta}_{O L S}$. The GM estimators of $\sigma_{1}^{2}, \sigma_{\nu}^{2}$ and $\rho$ are the solution of the sample counterpart of the six equations given above. Kapoor, et al. (2007) suggest three GM estimators. The first involves only the first three moments which do not involve $\sigma_{1}^{2}$ and yield estimates of $\rho$ and $\sigma_{\nu}^{2}$. The fourth moment condition is then used to solve for $\sigma_{1}^{2}$ given estimates of $\rho$ and $\sigma_{\nu}^{2}$. The second GM estimator is based upon weighing the moment equations by the inverse of a properly normalized variance-covariance matrix of the sample moments evaluated at the true parameter values. A simple version of this weighting matrix is derived under normality of the disturbances. The third GM estimator is motivated by computational considerations and replaces a component of the weighting matrix for the second GM estimator by an identity matrix. Kapoor, et al. (2007) perform Monte Carlo experiments comparing MLE and these three GM estimation methods. They find that on average, the RMSE of MLE and their weighted GM estimators are quite 
similar. The feasible GLS estimator of $\beta$ is then obtained by replacing $\rho, \sigma_{v}^{2}$ and $\sigma_{1}^{2}$ by their GM estimators. ${ }^{3}$

Recently, Fingleton (2007) extended this GM estimator for the SMA panel data model with random effects. We call this SMA-RE to distinguish it from the RE-SMA procedure described in Anselin, et al. (2008). In fact, for the Fingleton (2007) SMA-RE, the disturbance term $\varepsilon_{t}$ in (2) follows a SMA process and the remainder term follows an error component structure. Unlike the Anselin, et al. (2008) RE-SMA, the individual effects, i.e., the $\mu$ 's themselves are allowed to be spatially correlated but with the same $\lambda$. In particular, the disturbance vector for time $t$ is given by:

$$
\varepsilon_{t}=\left(I_{N}+\lambda W_{N}\right) u_{t}=D_{N} u_{t}
$$

where $D_{N}=\left(I_{N}+\lambda W_{N}\right)$, and $u_{t}$ follows an error component structure (14). So, the full SMA-RE $(N T \times 1)$ vector of disturbances is given by:

$$
\varepsilon=\left(\iota_{T} \otimes D_{N}\right) \mu+\left(I_{T} \otimes D_{N}\right) v
$$

and the corresponding $(N T \times N T)$ covariance matrix is given by:

$$
\Omega=\sigma_{\mu}^{2}\left(J_{T} \otimes\left(D_{N} D_{N}^{\prime}\right)\right)+\sigma_{v}^{2}\left[I_{T} \otimes\left(D_{N} D_{N}^{\prime}\right)\right]
$$

The moment conditions for SMA-RE are similar to those derived by Kapoor, et al. (2007), see Fingleton (2007).

\section{Prediction}

Goldberger (1962) has shown that, for a given $\Omega$, the best linear unbiased predictor (BLUP) for the $i$ th individual at a future period $T+\tau$ is given by:

$$
\widehat{y}_{i, T+\tau}=X_{i, T+\tau} \widehat{\beta}_{G L S}+\omega^{\prime} \Omega^{-1} \widehat{\varepsilon}_{G L S}
$$

where $\omega=E\left[\varepsilon_{i, T+\tau} \varepsilon\right]$ is the covariance between the future disturbance $\varepsilon_{i, T+\tau}$ and the sample disturbances $\varepsilon$. $\widehat{\beta}_{G L S}$ is the GLS estimator of $\beta$ from equation (1) based on $\Omega$ and $\widehat{\varepsilon}_{G L S}$ denotes the corresponding GLS residual vector.

\footnotetext{
${ }^{3}$ Later, in our Monte Carlo experiments, we computed the predictors for all three GM estimators suggested by Kapoor, et al. (2007). However, the differences in root mean squared error performance were minor. To save space, we only report the second GM estimator, called weighted GM estimator by Kapoor, et al. (2007).
} 
For the error component without spatial autocorrelation $(\lambda=0)$, this BLUP reduces to:

$$
\widehat{y}_{i, T+\tau}=X_{i, T+\tau} \widehat{\beta}_{G L S}+\frac{\sigma_{\mu}^{2}}{\sigma_{1}^{2}}\left(\iota_{T}^{\prime} \otimes l_{i}^{\prime}\right) \widehat{\varepsilon}_{G L S}
$$

where $\sigma_{1}^{2}=T \sigma_{\mu}^{2}+\sigma_{v}^{2}$ and $l_{i}$ is the $i$ th column of $I_{N}$. This predictor was considered by Wansbeek and Kapteyn (1978), Lee and Griffiths (1979) and Taub (1979). The typical element of the last term of equation (29) is $\left(T \sigma_{\mu}^{2} / \sigma_{1}^{2}\right) \bar{\varepsilon}_{i, G L S}$ where $\bar{\varepsilon}_{i ., G L S}=\sum_{t=1}^{T} \widehat{\varepsilon}_{t i, G L S} / T$. Therefore, the BLUP of $y_{i, T+\tau}$ for the RE model modifies the usual GLS forecasts by adding a fraction of the mean of the GLS residuals corresponding to the $i$ th individual. In order to make this forecast operational, $\widehat{\beta}_{G L S}$ is replaced by its feasible GLS estimate and the variance components are replaced by their feasible estimates.

Baltagi and $\mathrm{Li}(2004,2006)$ derived the BLUP correction term when both error components and spatial autocorrelation are present and $\phi_{t}$ follows a SAR process. So, the predictors for the SAR and the SMA are given by:

$$
\widehat{y}_{i, T+\tau}= \begin{cases}X_{i, T+\tau} \widehat{\beta}_{M L E}+\theta\left(\iota_{T}^{\prime} \otimes l_{i}^{\prime} C_{1}^{-1}\right) \widehat{\varepsilon}_{M L E} & \\ =X_{i, T+\tau} \widehat{\beta}_{M L E}+T \theta \sum_{j=1}^{N} c_{1, j} \bar{\varepsilon}_{j, M L E} & \text { for SAR } \\ X_{i, T+\tau} \widehat{\beta}_{M L E}+\theta\left(\iota_{T}^{\prime} \otimes l_{i}^{\prime} C_{2}^{-1}\right) \widehat{\varepsilon}_{M L E} & \\ =X_{i, T+\tau} \widehat{\beta}_{M L E}+T \theta \sum_{j=1}^{N} c_{2, j} \bar{\varepsilon}_{j, M L E} & \text { for SMA }\end{cases}
$$

where $c_{1 j}$ (resp. $c_{2, j}$ ) is the $j$ th element of the $i$ th row of $C_{1}^{-1}\left(\right.$ resp. $C_{2}^{-1}$ ) with $C_{1}=\left[T \theta I_{N}+\left(B_{N}^{\prime} B_{N}\right)^{-1}\right]$ (resp. $\left.C_{2}=\left[T \theta I_{N}+\left(D_{N} D_{N}^{\prime}\right)\right]\right)$ and $\bar{\varepsilon}_{j, M L E}=$ $\sum_{t=1}^{T} \widehat{\varepsilon}_{t j, M L E} / T$. In other words, the BLUP of $y_{i, T+\tau}$ adds to $X_{i, T+\tau} \widehat{\beta}_{M L E}$ a weighted average of the MLE residuals for the $N$ individuals averaged over time. The weights depend upon the spatial matrix $W_{N}$ and the spatial autoregressive (or moving average) coefficients $\rho$ and $\lambda$. To make these predictors operational, we replace $\theta, \rho$ and $\lambda$ by their estimates from the RE-spatial MLE with SAR or SMA. When there are no random individual effects, so that $\sigma_{\mu}^{2}=0$, then $\theta=0$ and the BLUP prediction terms drop out completely from equation (30). In these cases, $\Omega$ in equation (12) reduces to $\sigma_{v}^{2}\left[I_{T} \otimes\left(B_{N}^{\prime} B_{N}\right)^{-1}\right]$ for SAR and $\sigma_{v}^{2}\left[I_{T} \otimes\left(D_{N} D_{N}^{\prime}\right)\right]$ for SMA, and the corresponding MLE for these models yield the pooled spatial MLE with SAR or SMA remainder disturbances. 
For the Kapoor, et al. (2007) model, the BLUP of $y_{i, T+\tau}$ for the SAR-RE also modifies the usual GLS forecasts by adding a fraction of the mean of the GLS residuals corresponding to the $i$ th individual. More specifically, the predictor is given by:

$$
\widehat{y}_{i, T+\tau}=X_{i, T+\tau} \widehat{\beta}_{G L S}+\left(\frac{\sigma_{\mu}^{2}}{\sigma_{1}^{2}}\right) b_{i}\left(\iota_{T}^{\prime} \otimes B_{N}\right) \widehat{\varepsilon}_{G L S}
$$

where $b_{i}$ is the $i$ th row of the matrix $B_{N}^{-1}$. This is derived in the Appendix of this paper which also shows the resulting predictor has the same form as that of the RE model (29). This proof applies to both the Kapoor, et al. (2007) SAR-RE specification and the Fingleton (2007) SMA-RE specification. Therefore, the BLUP of $y_{i, T+\tau}$ for the SAR-RE and the SMA-RE, like the usual RE model with no spatial effects, modifies the usual GLS forecasts by adding a fraction of the mean of the GLS residuals corresponding to the $i$ th individual. While the predictor formula is the same, the MLEs for these specifications yield different estimates which in turn yield different residuals and hence different forecasts.

\section{Monte Carlo Design}

In this section, we consider the small sample performance of several predictors for an error component model with spatially autocorrelated residuals. The data generating process (DGP) consider two specifications on the remainder errors, namely SAR and SMA:

$$
y_{i t}=\beta_{0}+\beta_{1} x_{i t}+\varepsilon_{i t}, \varepsilon_{i t}=\mu_{i}+\phi_{i t}, i=1, \ldots, N ; t=1, \ldots, T
$$

where $^{4}$

$$
x_{i t}=\delta_{i}+\xi_{i t}
$$

with

$$
\begin{aligned}
& \mu_{i} \sim \operatorname{iid.N}\left(0, \sigma_{\mu}^{2}\right), \delta_{i} \sim i i d . U(-7.5,7.5), \\
& \xi_{i t} \sim \operatorname{iid.U}(-5,5), \beta_{0}=5, \beta_{1}=0.5
\end{aligned}
$$

\footnotetext{
${ }^{4}$ In the spirit of Nerlove (1971), we have tried another DGP for $x_{i t}$. We obtain the same ranking as those which appear in the reported tables. The only difference is that the gap between the average heterogeneous estimators and the homogeneous estimators widens with a Nerlove (1971) type design. In other words, the forecast performance of the heterogeneous estimators becomes worse.
} 


$$
\phi_{t}=\left\{\begin{array}{ll}
\rho W_{N} \phi_{t}+v_{t} & \text { for SAR } \\
\lambda W_{N} v_{t}+v_{t} & \text { for SMA }
\end{array} \text { with } \rho, \lambda=\left\{\begin{array}{l}
0.8 \\
0.4
\end{array}\right.\right.
$$

and

$$
v_{i t} \sim i i d . N\left(0, \sigma_{v}^{2}\right)
$$

We consider the simple regressions (32) and (33) with $N=(50,100), T=$ $(10,20)$ and two cases for the residuals variances:

$$
\begin{cases}\sigma_{\mu}^{2}=4, & \sigma_{v}^{2}=16 \\ \sigma_{\mu}^{2}=16, & \sigma_{v}^{2}=4\end{cases}
$$

Following Kelejian and Prucha (1999), we use two weight matrices which essentially differ in their degree of sparseness. The weight matrices are labelled as " $j$ ahead and $j$ behind" with the non-zero elements being $1 / 2 j, j=1$ and 5. Even with this modest design we have 64 experiments.

For each experiment, we obtain the following 16 estimators:

1. Pooled OLS which ignores the individual heterogeneity and the spatial autocorrelation.

2. The average heterogeneous OLS which estimates the cross-sectional equation using OLS for each time period and averages these heterogeneous estimates to obtain a pooled estimator, see Pesaran and Smith (1995).

3. The fixed-effects (FE) estimator which accounts for fixed individual effects but does not take into account the spatial autocorrelation.

4. The random effects (RE) estimator which asssumes that the $\mu_{i}$ 's are $i i d\left(0, \sigma_{\mu}^{2}\right)$, and independent of the remainder disturbances $\phi_{i t}$ 's. This estimator accounts for random individual effects but does not take into account the spatial autocorrelation.

5. The RE-spatial MLE assuming a SAR specification (RE-SAR) on the remainder disturbances. In this case, the $\mu_{i}$ 's are $i i d\left(0, \sigma_{\mu}^{2}\right)$ and are independent of the $\phi_{i t}$ 's which follow a SAR process, see Anselin, et al. (2008). 
6. The RE-spatial MLE assuming a SMA specification (RE-SMA) on the remainder disturbances. In this case, the $\mu_{i}^{\prime}$ 's are $i i d\left(0, \sigma_{\mu}^{2}\right)$ and are independent of the $\phi_{i t}$ 's which follow a SMA process, see Anselin, et al. (2008).

7. The pooled spatial MLE assuming a SAR specification (Pooled SAR) on the remainder disturbances. This estimator ignores the individual heterogeneity but takes into account the spatial autocorrelation of the SAR type.

8. The pooled spatial MLE assuming a SMA specification (Pooled SMA) on the remainder disturbances. This estimator ignores the individual heterogeneity but takes into account the spatial autocorrelation of the SMA type.

9. The average heterogeneous spatial MLE assuming a SAR specification on the remainder disturbances. This estimates cross-sectional MLE with SAR disturbances for each time period and averages the estimates over time.

10. The average heterogeneous spatial GM estimator assuming a SAR specification on the remainder disturbances proposed by Kelejian and Prucha (1999). This estimates cross-sectional GM estimator with SAR disturbances for each time period and averages the estimates over time.

11. The average heterogeneous spatial MLE assuming a SMA specification on the remainder disturbances. This estimates cross-sectional MLE with SMA disturbances for each time period and averages the estimates over time.

12. The average heterogeneous spatial GM estimator assuming a SMA specification on the remainder disturbances proposed by Fingleton (2007). This estimates cross-sectional GM estimator with SMA disturbances for each time period and averages the estimates over time.

13. The FE-spatial MLE assuming a SAR specification (FE-SAR) on the remainder disturbances.

14. The FE-spatial MLE assuming a SMA specification (FE-SMA) on the remainder disturbances. 
15. The (SAR-RE) model following Kapoor, et al. (2007). This utilizes a panel data GM estimator where the disturbance term itself follows a SAR process and the remainder term follows an error component structure.

16. The (SMA-RE) model following Fingleton (2007). This utilizes a panel data GM estimator where the disturbance term itself follows a SMA process and the remainder term follows an error component structure.

Next, we compute the following predictors for the $i$ th individual at a future period $T+\tau$ for $\tau=1,2, \ldots, 5$ :

\begin{tabular}{|c|c|}
\hline $\begin{array}{l}\text { OLS } \\
\text { Average hetero. OLS }\end{array}$ & $\begin{array}{l}\widehat{y}_{i, T+\tau}=X_{i, T+\tau} \widehat{\beta}_{O L S} \\
\widehat{y}_{i, T+\tau}=X_{i, T+\tau} \widehat{\beta}_{a v . O L S}\end{array}$ \\
\hline $\mathrm{FE}^{5}$ & $\left\{\begin{array}{l}\widehat{y}_{i, T+\tau}=X_{i, T+\tau} \widehat{\beta}_{F E}+\widehat{\mu}_{i} \\
\text { with } \widehat{\mu}_{i}=\bar{y}_{i}-\bar{X}_{i} \widehat{\beta}_{F E}, \bar{y}_{i}=\sum_{t=1}^{T} y_{i t} / T\end{array}\right.$ \\
\hline $\mathrm{RE}$ & $\widehat{y}_{i, T+\tau}=X_{i, T+\tau} \widehat{\beta}_{R E}+\frac{\sigma_{\mu}^{2}}{\sigma_{1}^{2}}\left(\iota_{T}^{\prime} \otimes l_{i}^{\prime}\right) \widehat{\varepsilon}_{R E}$ \\
\hline RE-SAR & $\left\{\begin{array}{l}\widehat{y}_{i, T+\tau}=X_{i, T+\tau} \widehat{\beta}_{M L E, R E-S A R}+\theta\left(\iota_{T}^{\prime} \otimes l_{i}^{\prime} C_{1}^{-1}\right) \widehat{\varepsilon}_{M L E, R E-S A R} \\
\text { with } C_{1}=\left[T \theta I_{N}+\left(B_{N}^{\prime} B_{N}\right)^{-1}\right] \text { and } \theta=\sigma_{\mu}^{2} / \sigma_{v}^{2}\end{array}\right.$ \\
\hline RE-SMA & $\left\{\begin{array}{l}\widehat{y}_{i, T+\tau}=X_{i, T+\tau} \widehat{\beta}_{M L E, R E-S M A}+\theta\left(\iota_{T}^{\prime} \otimes l_{i}^{\prime} C_{2}^{-1}\right) \widehat{\varepsilon}_{M L E, R E-S M A} \\
\text { with } C_{2}=\left[T \theta I_{N}+\left(D_{N} D_{N}^{\prime}\right)\right] \text { and } \theta=\sigma_{\mu}^{2} / \sigma_{v}^{2}\end{array}\right.$ \\
\hline Pooled SAR & $\widehat{y}_{i, T+\tau}=X_{i, T+\tau} \widehat{\beta}_{M L E, S A R}$ \\
\hline Pooled SMA & $\widehat{y}_{i, T+\tau}=X_{i, T+\tau} \widehat{\beta}_{M L E, S M A}$ \\
\hline Average hetero. SAR & $\widehat{y}_{i, T+\tau}=\left\{\begin{array}{l}X_{i, T+\tau} \widehat{\beta}_{a v \cdot M L E, S A R} \\
X_{i, T+\tau} \widehat{\beta}_{a v \cdot G M, S A R}\end{array}\right.$ \\
\hline Average hetero. SMA & $\widehat{y}_{i, T+\tau}=\left\{\begin{array}{l}X_{i, T+\tau} \widehat{\beta}_{a v \cdot M L E, S M A} \\
X_{i, T+\tau} \widehat{\beta}_{a v \cdot G M, S M A}\end{array}\right.$ \\
\hline FE-SAR & $\begin{array}{l}\widehat{y}_{i, T+\tau}=X_{i, T+\tau} \widehat{\beta}_{M L E, F E-S A R}+\widehat{\mu}_{i} \\
\text { with } \widehat{\mu}_{i}=\bar{y}_{i}-\bar{X}_{i} \widehat{\beta}_{M L E, F E-S A R}, \bar{y}_{i}=\sum_{t=1}^{T} y_{i t} / T\end{array}$ \\
\hline FE-SMA & $\left\{\begin{array}{l}\widehat{y}_{i, T+\tau}=X_{i, T+\tau} \widehat{\beta}_{M L E, F E-S M A}+\widehat{\mu}_{i} \\
\text { with } \widehat{\mu}_{i}=\bar{y}_{i}-\bar{X}_{i} \widehat{\beta}_{M L E, F E-S M A}, \bar{y}_{i}=\sum_{t=1}^{T} y_{i t} / T\end{array}\right.$ \\
\hline SAR-RE & $\widehat{y}_{i, T+\tau}=X_{i, T+\tau} \widehat{\beta}_{M L E, S A R-R E}+\left(\frac{\sigma_{\mu}^{2}}{\sigma_{1}^{2}}\right)\left(\iota_{T}^{\prime} \otimes l_{i}^{\prime}\right) \widehat{\varepsilon}_{M L E, S A R-R E}$ \\
\hline SMA-RE & $\widehat{y}_{i, T+\tau}=X_{i, T+\tau} \widehat{\beta}_{M L E, S M A-R E}+\left(\frac{\sigma_{\mu}^{2}}{\sigma_{1}^{2}}\right)\left(\iota_{T}^{\prime} \otimes l_{i}^{\prime}\right) \widehat{\varepsilon}_{M L E, S M A-R E}$ \\
\hline
\end{tabular}


For all experiments, 1000 replications are performed and the RMSE for one step to five step ahead forecasts are reported.

\section{Monte Carlo Results}

\subsection{The Spatial Dependence Specification Effect}

Table 1 gives the RMSE for the one year, two year,..., and five year ahead forecasts along with the average RMSE for all 5 years. These are out of sample forecasts when the true DGP is a RE panel model with SAR remainder disturbances. The sample size is $N=50$ and $T=10$, the weight matrix is $\mathrm{W}(1,1)$, i.e., one neighbor behind and one neighbor ahead. In general, for $\rho=0.4,0.8$ and $\sigma_{\mu}^{2}=4,16$, the lowest RMSE is that of RE-SAR. This is followed closely by SAR-RE and SMA-RE. It confirms the findings of Kapoor, et al. (2007) that, on average, RMSE of MLE and their GM estimators are quite similar. It also seems like misspecifying the SAR by an SMA in an error component model does not affect the forecast performance as long as it is taken into account. As the spatial autoregressive parameter $\rho$ doubles from 0.4 to 0.8 , the RMSE also doubles. The RMSE improves as $\sigma_{\mu}^{2}$ gets large, i.e., 16 rather than 4, for estimators that take heterogeneity into account. Pooled OLS, average heterogeneous OLS, pooled SAR, pooled SMA, average heterogeneous SAR (MLE and GM) and average heterogeneous SMA (MLE and GM) perform worse in terms of RMSE than spatial/panel homogeneous estimators. This forecast comparison is robust whether we are predicting one period, two periods or 5 periods ahead and is also reflected in the average over the five years. The gain in forecast performance is substantial once we account for RE or FE and is only slightly improved by additionally accounting for spatial autocorrelation, i.e., FE-SAR or RE-SAR, FE-SMA, or RE-SMA.

Table 2 gives the RMSE results when the true DGP is a RE panel model with SMA remainder disturbances. The sample size is still $N=50, T=10$, and the weight matrix is $\mathrm{W}(1,1)$. In general, for $\rho=0.4,0.8$ and $\sigma_{\mu}^{2}=4,16$, the lowest RMSE is that of RE-SMA. This is followed closely by RE-SAR.

\footnotetext{
${ }^{5}$ See Baillie and Baltagi (1998).
} 
Misspecifying the SMA by an SAR in an error component model does not seem to affect the forecast performance as long as it is taken into account. However, the magnitudes of the RMSE in Table 2 (where the true DGP is a RE-SMA process) are much lower than those in Table 1 (where the true DGP is a RE-SAR process). Once again, the forecast RMSE of based on MLE and their GM counterparts are quite similar, compare SAR-RE and SMA-RE with RE-SAR and RE-SMA. The RMSE improves as $\sigma_{\mu}^{2}$ gets large, i.e., 16 rather than 4 , for estimators that take heterogeneity into account. As the spatial autoregressive parameter $\lambda$ increases from 0.4 to 0.8 , the RMSE also increases but not as much as it did for the SAR process in Table 1. Pooled OLS, average heterogeneous OLS, pooled SAR, pooled SMA, average heterogeneous SAR (MLE and GM) and average heterogeneous SMA (MLE and GM) perform worse in terms of RMSE than spatial/panel homogeneous estimators. This forecast performance is robust whether we are predicting one period, two periods or 5 periods ahead and is also reflected in the average over the five years. Once again, the gain in forecast performance is substantial once we account for $\mathrm{RE}$ or $\mathrm{FE}$ and is only slightly improved by additionally accounting for spatial autocorrelation, i.e., FE-SMA, or RE-SMA, FE-SAR or RE-SAR.

\subsection{Sensitivity Analysis}

\subsubsection{The Spatial Weight Matrix effect}

Tables 3 and 4 report the RMSE results as Tables 1 and 2 except that the weight matrix is changed from a $W(1,1)$ to $W(5,5)$, i.e., five neighbors behind and five neighbors ahead. Except for the magnitudes of the RMSE, the same rankings in terms of RMSE performance are exhibited as before.

Tables 5 and 6 report the RMSE results as Tables 1 and 2 except that $T$ is now doubled from 10 to 20 holding $N$ fixed at 50. Except for the magnitudes of the RMSE, the same rankings in terms of RMSE performance are exhibited as before.

Table 7 reports the RMSE results when $\rho=\lambda=0.8$, the weight matrix is $W(1,1)$, and $N$ is doubled from 50 to 100 holding $T$ fixed at 10 . While Table 8 reports the RMSE results as Table 7 except that the weight matrix is $W(5,5)$. Except for the magnitudes of the RMSE, the same rankings in terms of RMSE performance are exhibited as before. ${ }^{6}$

\footnotetext{
${ }^{6}$ Other Tables for $W(5,5)$ and $(N, T)=(100,20)$ show the same rankings in terms of
} 


\subsubsection{Sensitivity to Irregular Lattice Structures}

The spatial weights matrices considered in the paper are regular lattice structures. Using real irregular lattices structures, as in Anselin and Moreno (2003) and in Kelejian and Prucha (1999), does not change the conclusions of the Monte Carlo study. We used real-world matrices by taking spatial groupings of French administrative communes for dimension $N=50 .{ }^{7}$ Those spatial matrices have been used by Baltagi, Bresson and Pirotte (2007). Spatial weight matrices may represent high-order contiguity relationships. We use a $k$-order contiguity matrix containing $N-1$ potential neighborhoods in French municipalities. We have patterns of 0 and 1 values in an $(N-1)$ by $(N-1)$ grid for the $k$-nearest neighborhoods and we use the 1-nearest neighborhood $(k=1)$ and the 5 -nearest neighborhoods $(k=1)^{8}$. Results of Tables 9 to 12 are very similar to those of Tables 1 to 4 . Using irregular lattice structures do not change the main conclusions in terms of the RMSE forecast performance of the various estimators considered. These are similar to the rankings obtained when regular lattice structures are used, only the magnitudes of the RMSE differ.

\subsubsection{Robustness to Non-Normality}

So far, we have been assuming that the error components have been generated by the normal distribution. In this section, we check the sensitivity of our results to non-normal disturbances. In particular, we generate the $\mu_{i}$ 's from a $\chi^{2}$ distribution and we let the remainder disturbances follow the normal distribution. Tables 13 and 14 give similar results as those of Tables 1 and 2 (when the individual effects follow a normal distribution). So, the results seem to be robust to non-normality of the disturbances of the $\chi^{2}$ type.

RMSE forecast performance and are not shown here to save space. These are available upon request from the authors.

${ }^{7}$ Other Tables for $N=100$ are available upon request from the authors.

${ }^{8}$ Note that a non-zero entry in row $i$, column $j$ denotes that neighborhoods $i$ and $j$ have borders that touch and are therefore considered "neighbors". For $N=50$ and for $k=5$, and for the 2401 possible elements in the 49 by 49 matrix, there are only 250 non-zero elements. So, the sparseness value is $10 \%(=250 / 2500)$. These non-zero entries reflect the contiguity relations between the 5 -nearest neighborhoods. 


\section{Summary and Conclusion}

Our Monte Carlo study finds that when the true DGP is RE with a SAR or SMA remainder disturbances, estimators that ignore heterogeneity/spatial correlation perform badly in RMSE forecasts. For our experiments, accounting for heterogeneity improves the forecast performance by a big margin and accounting for spatial correlation improves the forecast but by a smaller margin. Ignoring both leads to the worst forecasting performance. Heterogeneous estimators based on averaging perform worse than homogeneous estimators in forecasting performance. This performance improves with a larger sample size and seems robust to the type of spatial error structure imposed on the remainder disturbances. These Monte Carlo experiments confirm earlier empirical studies that report similar findings.

\section{Appendix}

This appendix first derives the BLUP for the KKP model which we are calling the (SAR-RE) model described in (13) and (14). The variance-covariance matrix $\Omega$ is given in (17). The inverse of $\Omega$ is given by:

$$
\Omega^{-1}=\frac{1}{\sigma_{v}^{2}}\left[\left(I_{T}-\frac{T \sigma_{\mu}^{2}}{\sigma_{1}^{2}} \bar{J}_{T}\right) \otimes\left(B_{N}^{\prime} B_{N}\right)\right]
$$

where $\bar{J}_{T}=J_{T} / T$ and $\sigma_{1}^{2}=T \sigma_{\mu}^{2}+\sigma_{v}^{2}$ and $B_{N}=\left(I_{N}-\rho W_{N}\right)$. From (13) and (14), we have :

$$
\varepsilon_{T+\tau}=B_{N}^{-1} u_{T+\tau}=B_{N}^{-1}\left(\mu+v_{T+\tau}\right)
$$

so that,

$$
\begin{aligned}
E\left[\varepsilon_{T+\tau} \varepsilon^{\prime}\right]= & E\left[B_{N}^{-1}\left(\mu+v_{T+\tau}\right)\left(\left(\iota_{T} \otimes B_{N}^{-1}\right) \mu+\left(I_{T} \otimes B_{N}^{-1}\right) v\right)^{\prime}\right] \\
= & \sigma_{\mu}^{2} B_{N}^{-1}\left(\iota_{T}^{\prime} \otimes B_{N}^{-1^{\prime}}\right) \\
& \omega^{\prime}=E\left[\varepsilon_{i, T+\tau} \varepsilon^{\prime}\right]=\sigma_{\mu}^{2} b_{i}\left(\iota_{T}^{\prime} \otimes B_{N}^{-1^{\prime}}\right)
\end{aligned}
$$

where $b_{i}$ is the $i$ th row of the matrix $B_{N}^{-1}$. In this case,

$$
\omega^{\prime} \Omega^{-1}=\frac{\sigma_{\mu}^{2}}{\sigma_{v}^{2}} b_{i}\left(\iota_{T}^{\prime} \otimes B_{N}^{-1^{\prime}}\right)\left[\left(I_{T}-\frac{T \sigma_{\mu}^{2}}{\sigma_{1}^{2}} \bar{J}_{T}\right) \otimes\left(B_{N}^{\prime} B_{N}\right)\right]
$$




$$
\begin{aligned}
& =\frac{\sigma_{\mu}^{2}}{\sigma_{v}^{2}} b_{i}\left[\left(\iota_{T}^{\prime} \otimes B_{N}\right)-\frac{T \sigma_{\mu}^{2}}{\sigma_{1}^{2}}\left(\iota_{T}^{\prime} \otimes B_{N}\right)\right] \\
& =\frac{\sigma_{\mu}^{2}}{\sigma_{1}^{2}} b_{i}\left(\iota_{T}^{\prime} \otimes B_{N}\right)
\end{aligned}
$$

But $b_{i}\left(\iota_{T}^{\prime} \otimes B_{N}\right)=\left(1 \otimes b_{i}\right)\left(\iota_{T}^{\prime} \otimes B_{N}\right)=\left(\iota_{T}^{\prime} \otimes l_{i}^{\prime}\right)$, where $l_{i}^{\prime}$ is the $i$ th row of $I_{N}$. This holds because $B_{N}^{-1} B_{N}=I_{N}$ and therefore $b_{i} B_{N}=l_{i}^{\prime}$. This means that the predictor of the KKP model from (28) is given by:

$$
\widehat{y}_{i, T+\tau}=X_{i, T+\tau} \widehat{\beta}_{G L S}+\frac{\sigma_{\mu}^{2}}{\sigma_{1}^{2}}\left(\iota_{T}^{\prime} \otimes l_{i}^{\prime}\right) \widehat{\varepsilon}_{G L S}
$$

which is the same as that of the RE model with no spatial correlation. While the predictor formula is the same, the MLEs for these specifications yield different estimates which in turn yield different residuals and hence different forecasts.

The proof is the similar for the Fingleton (2007) specification which we are calling the (SMA-RE) model described in (25) and (14). The variancecovariance matrix $\Omega$ is given in (27). The inverse of $\Omega$ is given by:

$$
\Omega^{-1}=\frac{1}{\sigma_{v}^{2}}\left[\left(I_{T}-\frac{T \sigma_{\mu}^{2}}{\sigma_{1}^{2}} \bar{J}_{T}\right) \otimes\left(D_{N} D_{N}^{\prime}\right)^{-1}\right]
$$

where $D_{N}=\left(I_{N}+\lambda W_{N}\right)$. From (25) and (14), we have :

$$
\varepsilon_{T+\tau}=D_{N} u_{T+\tau}=D_{N}\left(\mu+v_{T+\tau}\right)
$$

so that,

$$
\begin{aligned}
E\left[\varepsilon_{T+\tau} \varepsilon^{\prime}\right]= & E\left[D_{N}\left(\mu+v_{T+\tau}\right)\left(\left(\iota_{T} \otimes D_{N}\right) \mu+\left(I_{T} \otimes D_{N}\right) v\right)^{\prime}\right] \\
= & \sigma_{\mu}^{2} D_{N}\left(\iota_{T}^{\prime} \otimes D_{N}^{\prime}\right) \\
& \omega^{\prime}=E\left[\varepsilon_{i, T+\tau} \varepsilon^{\prime}\right]=\sigma_{\mu}^{2} d_{i}\left(\iota_{T}^{\prime} \otimes D_{N}^{\prime}\right)
\end{aligned}
$$

where $d_{i}$ is the $i$ th row of the matrix $D_{N}$. In this case,

$$
\begin{aligned}
\omega^{\prime} \Omega^{-1} & =\frac{\sigma_{\mu}^{2}}{\sigma_{v}^{2}} d_{i}\left(\iota_{T}^{\prime} \otimes D_{N}^{\prime}\right)\left[\left(I_{T}-\frac{T \sigma_{\mu}^{2}}{\sigma_{1}^{2}} \bar{J}_{T}\right) \otimes\left(D_{N} D_{N}^{\prime}\right)^{-1}\right] \\
& =\frac{\sigma_{\mu}^{2}}{\sigma_{v}^{2}} d_{i}\left[\left(\iota_{T}^{\prime} \otimes D_{N}^{-1}\right)-\frac{T \sigma_{\mu}^{2}}{\sigma_{1}^{2}}\left(\iota_{T}^{\prime} \otimes D_{N}^{-1}\right)\right] \\
& =\frac{\sigma_{\mu}^{2}}{\sigma_{1}^{2}} d_{i}\left(\iota_{T}^{\prime} \otimes D_{N}^{-1}\right)
\end{aligned}
$$


But $d_{i}\left(\iota_{T}^{\prime} \otimes D_{N}^{-1}\right)=\left(1 \otimes d_{i}\right)\left(\iota_{T}^{\prime} \otimes D_{N}^{-1}\right)=\left(\iota_{T}^{\prime} \otimes l_{i}^{\prime}\right)$, where $l_{i}^{\prime}$ is the $i$ th row of $I_{N}$. This holds because $D_{N} D_{N}^{-1}=I_{N}$ and therefore $d_{i} D_{N}^{-1}=l_{i}^{\prime}$. This means that the predictor of the Fingleton (2007) model is again the same as that of the RE model with no spatial correlation. While the predictor formula is the same, the MLEs for these specifications yield different estimates which in turn yield different residuals and hence different forecasts. 


\section{References}

Anselin, L., 1988, Spatial Econometrics: Methods and Models, Kluwer Academic Publishers, Dordrecht.

Anselin, L. and A.K. Bera, 1998, Spatial dependence in linear regression models with an introduction to spatial econometrics. In A. Ullah and D.E.A. Giles, eds., Handbook of Applied Economic Statistics, Marcel Dekker, New York.

Anselin, L. and R. Moreno, 2003, Properties of tests for spatial error components, Regional Science and Urban Economics 33, 595-618.

Anselin, L., J. Le Gallo and H. Jayet, 2008, Spatial panel econometrics. Ch. 19 in L. Mátyás and P. Sevestre, eds., The Econometrics of Panel Data: Fundamentals and Recent Developments in Theory and Practice, Springer-Verlag, Berlin, 625-660.

Baillie, R.T. and B.H. Baltagi, 1999, Prediction from the regression model with one-way error components, Chapter 10 in C. Hsiao, K. Lahiri, L.F. Lee and H. Pesaran, eds., Analysis of Panels and Limited Dependent Variable Models, Cambridge University Press, Cambridge, 255-267.

Baltagi, B.H., 2008, Forecasting with panel data, Journal of Forecasting 27, 153-173..

Baltagi, B.H. and J.M. Griffin, 1997, Pooled estimators vs. their heterogeneous counterparts in the context of dynamic demand for gasoline, Journal of Econometrics 77, 303-327.

Baltagi, B.H. and D. Li, 2004, Prediction in the panel data model with spatial correlation, Chapter 13 in L. Anselin, R.J.G.M. Florax and S.J. Rey, eds., Advances in Spatial Econometrics: Methodology, Tools and Applications, Springer, Berlin, 283-295.

Baltagi, B.H. and D. Li, 2006, Prediction in the panel data model with spatial correlation: The case of liquor, Spatial Economic Analysis 1, 175-185.

Baltagi, B.H. and Q. Li, 1992, Prediction in the one-way error component model with serial correlation, Journal of Forecasting 11, 561-567.

Baltagi, B.H., G. Bresson and A. Pirotte, 2002, Comparison of forecast performance for homogeneous, heterogeneous and shrinkage estimators: Some empirical evidence from US electricity and natural-gas consumption, Economics Letters 76, 375-382. 
Baltagi, B.H., G. Bresson and A. Pirotte, 2004, Tobin q: forecast performance for hierarchical Bayes, shrinkage, heterogeneous and homogeneous panel data estimators, Empirical Economics 29, 107-113.

Baltagi, B.H., G. Bresson and A. Pirotte, 2007, Panel unit root tests and spatial dependence, Journal of Applied Econometrics 22, 339-360.

Baltagi, B.H., J.M. Griffin and W. Xiong, 2000, To pool or not to pool: Homogeneous versus heterogeneous estimators applied to cigarette demand, Review of Economics and Statistics 82, 117-126.

Brucker, H. and B. Siliverstovs, 2006, On the estimation and forecasting of international migration: how relevant is heterogeneity across countries, Empirical Economics 31, 735-754.

Fingleton, B., 2007a, A generalized method of moments estimator for a spatial model with endogenous spatial lag and spatial moving average errors, paper presented at the 13th international conference on panel data, University of Cambridge, forthcoming Spatial Economic Analysis.

Fingleton, B., 2007b, A generalized method of moments estimator for a spatial model with moving average errors with application to real estate prices, forthcoming in Empirical Economics.

Frees, E.W. and T.W. Miller, 2004, Sales forecasting using longitudinal data models. International Journal of Forecasting 20, 99-114.

Goldberger, A.S., 1962, Best linear unbiased prediction in the generalized linear regression model, Journal of the American Statistical Association 57, 369-375.

Kapoor, M., H.H. Kelejian and I.R. Prucha, 2007, Panel data models with spatially correlated error components, Journal of Econometrics 140, 97-130.

Kelejian, H.H. and I.R. Prucha, 1999, A generalized moments estimator for the autoregressive parameter in a spatial model, International Economic Review 40, 509-533.

Lee, L.F. and W.E. Griffiths, 1979, The prior likelihood and best linear unbiased prediction in stochastic coefficient linear models, working paper, Department of Economics, University of Minnesota. 
Hoogstrate, A.J., F.C. Palm and G.A. Pfann, 2000, Pooling in dynamic panel-data models: An application to forecasting GDP growth rates, Journal of Business and Economic Statistics 18, 274-283.

Hsiao, C. and A.K. Tahmiscioglu, 1997, A panel analysis of liquidity constraints and firm investment, Journal of the American Statistical Association 92, 455-465.

Nerlove, M., 1971, Futher evidence on the estimation of dynamic economic relations from a time-series of cross-sections, Econometrica 39, 359-382.

Pesaran, M.H. and R. Smith, 1995, Estimating long-run relationships from dynamic heterogenous panels, Journal of Econometrics 68, 79-113.

Rapach, D.E. and M.E. Wohar, 2004, Testing the monetary model of exchange rate determination: a closer look at panels, Journal of International Money and Finance $23,867-895$.

Schmalensee, R., T.M. Stoker and R.A. Judson, 1998, World carbon dioxide emissions: 1950-2050, Review of Economics and Statistics 80, 15-27.

Spanos, A., 2002, The ET interview: Professor Phoebus J. Dhrymes, Econometric Theory $18,1221-1272$.

Taub, A.J., 1979, Prediction in the context of the variance-components model, Journal of Econometrics 10, 103-108.

Theil, H., 1961, Economic Forecasts and Policy, North-Holland, Amsterdam.

Wansbeek, T.J. and A. Kapteyn, 1978, The seperation of individual variation and systematic change in the analysis of panel data, Annales de l'INSEE 30-31, 659-680. 
Table 1 - Forecasts RMSE - $(\mathrm{N}, \mathrm{T})=(50,10)$, SAR data generating process for $\phi, W(1,1), 1000$ replications

\begin{tabular}{|c|c|c|c|c|c|c|c|c|c|c|c|c|c|c|c|c|c|c|}
\hline & \multicolumn{18}{|c|}{ Estimators } \\
\hline & \multirow[b]{2}{*}{$\rho$} & \multirow[b]{2}{*}{$\sigma_{\mu}^{2}$} & \multirow{2}{*}{$\begin{array}{c}\text { Pooled } \\
\text { OLS }\end{array}$} & \multirow{2}{*}{$\begin{array}{l}\text { Av. hetero. } \\
\text { OLS }\end{array}$} & \multirow{2}{*}{ FE } & \multirow{2}{*}{$\mathrm{RE}$} & \multirow{2}{*}{$\begin{array}{c}\text { Pooled SAR } \\
\text { MLE }\end{array}$} & \multicolumn{2}{|c|}{ Av. hetero. SAR } & \multirow{2}{*}{$\begin{array}{c}\text { FE-SAR } \\
\text { MLE }\end{array}$} & \multirow{2}{*}{$\begin{array}{c}\text { RE-SAR } \\
\text { MLE }\end{array}$} & \multirow{2}{*}{$\begin{array}{c}\text { Pooled SMA } \\
\text { MLE }\end{array}$} & \multicolumn{2}{|c|}{ Av. hetero. SMA } & \multirow{2}{*}{$\begin{array}{c}\text { FE-SMA } \\
\text { MLE }\end{array}$} & \multirow{2}{*}{$\begin{array}{c}\text { RE-SMA } \\
\text { MLE }\end{array}$} & \multirow{2}{*}{$\begin{array}{c}\text { SAR-RE } \\
\text { GM }\end{array}$} & \multirow{2}{*}{$\begin{array}{c}\text { SMA-RE } \\
\text { GM }\end{array}$} \\
\hline & & & & & & & & MLE & GM & & & & MLE & GM & & & & \\
\hline \multirow{4}{*}{ 1st year } & 0.4 & 4 & 3.9781 & 3.9782 & 3.8102 & 3.7645 & 3.9781 & 3.9781 & 3.9606 & 3.8093 & 3.7558 & 3.9782 & 3.9782 & 3.9464 & 3.8093 & 3.7558 & 3.7610 & 3.7765 \\
\hline & & 16 & 3.6289 & 3.6290 & 1.9019 & 1.8989 & 3.6300 & 3.6299 & 3.6522 & 1.9007 & 1.8971 & 3.6301 & 3.6300 & 3.6569 & 1.9007 & 1.8973 & 1.8978 & 1.9134 \\
\hline & 0.8 & 4 & 7.0556 & 7.0552 & 7.1957 & 7.0218 & 7.0529 & 7.0389 & 7.0558 & 7.1917 & 6.9564 & 7.0541 & 7.0403 & 7.0796 & 7.1917 & 6.9668 & 7.0187 & 7.0382 \\
\hline & & 16 & 4.6529 & 4.6533 & 3.5908 & 3.5764 & 4.6584 & 4.6569 & 4.6697 & 3.5863 & 3.5518 & 4.6589 & 4.6576 & 4.6644 & 3.5867 & 3.5603 & 3.6047 & 3.5908 \\
\hline \multirow{4}{*}{ 2nd year } & 0.4 & 4 & 4.4164 & 4.4165 & 4.2360 & 4.1840 & 4.4162 & 4.4162 & 4.3423 & 4.2354 & 4.1763 & 4.4164 & 4.4164 & 4.3721 & 4.2353 & 4.1755 & 4.1808 & 4.1739 \\
\hline & & 16 & 3.8731 & 3.8733 & 2.1207 & 2.1175 & 3.8742 & 3.8743 & 3.8849 & 2.1194 & 2.1155 & 3.8742 & 3.8744 & 3.8918 & 2.1195 & 2.1156 & 2.1164 & 2.1216 \\
\hline & 0.8 & 4 & 7.8106 & 7.8106 & 7.9469 & 7.7633 & 7.8066 & 7.7911 & 7.8100 & 7.9408 & 7.6956 & 7.8073 & 7.7920 & 7.8306 & 7.9407 & 7.7034 & 7.7832 & 7.8190 \\
\hline & & 16 & 5.1174 & 5.1177 & 4.0090 & 3.9942 & 5.1221 & 5.1209 & 5.1206 & 4.0039 & 3.9661 & 5.1225 & 5.1213 & 5.1084 & 4.0042 & 3.9754 & 3.9923 & 3.9833 \\
\hline \multirow{4}{*}{ 3rd year } & 0.4 & 4 & 4.5807 & 4.5808 & 4.3992 & 4.3445 & 4.5805 & 4.5805 & 4.5627 & 4.3986 & 4.3364 & 4.5806 & 4.5807 & 4.5560 & 4.3985 & 4.3357 & 4.3414 & 4.3475 \\
\hline & & 16 & 3.9582 & 3.9585 & 2.2004 & 2.1972 & 3.9591 & 3.9592 & 3.9660 & 2.1992 & 2.1954 & 3.9591 & 3.9594 & 3.9682 & 2.1993 & 2.1956 & 2.1963 & 2.2023 \\
\hline & 0.8 & 4 & 8.1467 & 8.1467 & 8.2921 & 8.1023 & 8.1424 & 8.1273 & 8.1458 & 8.2853 & 8.0289 & 8.1430 & 8.1279 & 8.1618 & 8.2854 & 8.0382 & 8.1016 & 8.1402 \\
\hline & & 16 & 5.2892 & 5.2894 & 4.1685 & 4.1529 & 5.2936 & 5.2923 & 5.2763 & 4.1636 & 4.1234 & 5.2940 & 5.2928 & 5.2674 & 4.1640 & 4.1337 & 4.1387 & 4.1450 \\
\hline \multirow{4}{*}{ 4th year } & 0.4 & 4 & 4.6719 & 4.6720 & 4.4891 & 4.4335 & 4.6718 & 4.6717 & 4.6676 & 4.4882 & 4.4250 & 4.6719 & 4.6720 & 4.6583 & 4.4881 & 4.4245 & 4.4301 & 4.4332 \\
\hline & & 16 & 4.0024 & 4.0026 & 2.2471 & 2.2440 & 4.0031 & 4.0033 & 4.0117 & 2.2460 & 2.2423 & 4.0032 & 4.0034 & 4.0125 & 2.2461 & 2.2424 & 2.2432 & 2.2451 \\
\hline & 0.8 & 4 & 8.3035 & 8.3035 & 8.4435 & 8.2560 & 8.2997 & 8.2836 & 8.3011 & 8.4367 & 8.1826 & 8.3005 & 8.2843 & 8.3225 & 8.4370 & 8.1922 & 8.3142 & 8.3214 \\
\hline & & 16 & 5.3799 & 5.3802 & 4.2531 & 4.2377 & 5.3838 & 5.3826 & 5.3662 & 4.2481 & 4.2085 & 5.3841 & 5.3829 & 5.3626 & 4.2485 & 4.2183 & 4.2296 & 4.2143 \\
\hline \multirow{4}{*}{ 5th year } & 0.4 & 4 & 4.7238 & 4.7239 & 4.5443 & 4.4870 & 4.7238 & 4.7238 & 4.7274 & 4.5432 & 4.4778 & 4.7239 & 4.7240 & 4.7199 & 4.5432 & 4.4775 & 4.4836 & 4.4906 \\
\hline & & 16 & 4.0283 & 4.0285 & 2.2727 & 2.2698 & 4.0288 & 4.0290 & 4.0362 & 2.2716 & 2.2681 & 4.0289 & 4.0291 & 4.0374 & 2.2716 & 2.2682 & 2.2689 & 2.2718 \\
\hline & 0.8 & 4 & 8.4195 & 8.4197 & 8.5680 & 8.3756 & 8.4158 & 8.3995 & 8.4173 & 8.5606 & 8.2997 & 8.4164 & 8.4001 & 8.4331 & 8.5608 & 8.3100 & 8.4299 & 8.4256 \\
\hline & & 16 & 5.4280 & 5.4282 & 4.2962 & 4.2812 & 5.4313 & 5.4301 & 5.4156 & 4.2911 & 4.2526 & 5.4317 & 5.4305 & 5.4125 & 4.2914 & 4.2618 & 4.2808 & 4.2710 \\
\hline \multirow{4}{*}{ Average } & 0.4 & 4 & 4.4742 & 4.4743 & 4.2957 & 4.2427 & 4.4741 & 4.4740 & 4.4601 & 4.2949 & 4.2343 & 4.4742 & 4.4743 & 4.4505 & 4.2949 & 4.2338 & 4.2394 & 4.2444 \\
\hline & & 16 & 3.8982 & 3.8984 & 2.1486 & 2.1455 & 3.8990 & 3.8992 & 3.9102 & 2.1474 & 2.1437 & 3.8991 & 3.8993 & 3.9133 & 2.1474 & 2.1438 & 2.1445 & 2.1509 \\
\hline & 0.8 & 4 & 7.9472 & 7.9471 & 8.0892 & 7.9038 & 7.9435 & 7.9281 & 7.9460 & 8.0830 & 7.8326 & 7.9443 & 7.9289 & 7.9655 & 8.0831 & 7.8421 & 7.9295 & 7.9489 \\
\hline & & 16 & 5.1735 & 5.1738 & 4.0635 & 4.0485 & 5.1778 & 5.1766 & 5.1697 & 4.0586 & 4.0205 & 5.1782 & 5.1770 & 5.1631 & 4.0589 & 4.0299 & 4.0492 & 4.0409 \\
\hline
\end{tabular}


Table 2 - Forecasts RMSE - $(\mathrm{N}, \mathrm{T})=(\mathbf{5 0 , 1 0 )}$, SMA data generating process for $\phi, W(\mathbf{1}, \mathbf{1}), 1000$ replications

\begin{tabular}{|c|c|c|c|c|c|c|c|c|c|c|c|c|c|c|c|c|c|c|}
\hline & \multicolumn{18}{|c|}{ Estimators } \\
\hline & \multirow[b]{2}{*}{$\lambda$} & \multirow[b]{2}{*}{$\sigma_{\mu}^{2}$} & \multirow{2}{*}{$\begin{array}{c}\text { Pooled } \\
\text { OLS }\end{array}$} & \multirow{2}{*}{$\begin{array}{c}\text { Av. hetero. } \\
\text { OLS }\end{array}$} & \multirow{2}{*}{ FE } & \multirow{2}{*}{$\mathrm{RE}$} & \multirow{2}{*}{$\begin{array}{c}\text { Pooled SAR } \\
\text { MLE }\end{array}$} & \multicolumn{2}{|c|}{ Av. hetero. SAR } & \multirow{2}{*}{$\begin{array}{c}\text { FE-SAR } \\
\text { MLE }\end{array}$} & \multirow{2}{*}{$\begin{array}{c}\text { RE-SAR } \\
\text { MLE }\end{array}$} & \multirow{2}{*}{$\begin{array}{c}\text { Pooled SMA } \\
\text { MLE }\end{array}$} & \multicolumn{2}{|c|}{ Av. hetero. SMA } & \multirow{2}{*}{$\begin{array}{c}\text { FE-SMA } \\
\text { MLE }\end{array}$} & \multirow{2}{*}{$\begin{array}{c}\text { RE-SMA } \\
\text { MLE }\end{array}$} & \multirow{2}{*}{$\begin{array}{c}\text { SAR-RE } \\
\text { GM }\end{array}$} & \multirow{2}{*}{$\begin{array}{c}\text { SMA-RE } \\
\text { GM }\end{array}$} \\
\hline & & & & & & & & MLE & GM & & & & MLE & GM & & & & \\
\hline \multirow{4}{*}{1 st year } & 0.4 & 4 & 3.6702 & 3.6703 & 3.4717 & 3.4261 & 3.6704 & 3.6701 & 3.6706 & 3.4707 & 3.4193 & 3.6705 & 3.6702 & 3.6669 & 3.4707 & 3.4187 & 3.4330 & 3.4375 \\
\hline & & 16 & 3.5582 & 3.5582 & 1.7481 & 1.7455 & 3.5583 & 3.5584 & 3.5606 & 1.7478 & 1.7450 & 3.5584 & 3.5585 & 3.5569 & 1.7479 & 1.7449 & 1.7444 & 1.7323 \\
\hline & 0.8 & 4 & 3.9870 & 3.9873 & 3.8507 & 3.7906 & 3.9857 & 3.9856 & 3.9878 & 3.8481 & 3.7653 & 3.9858 & 3.9859 & 3.9770 & 3.8480 & 3.7635 & 3.7915 & 3.8213 \\
\hline & & 16 & 3.6364 & 3.6364 & 1.9117 & 1.9095 & 3.6381 & 3.6377 & 3.6235 & 1.9098 & 1.9068 & 3.6380 & 3.6376 & 3.6316 & 1.9097 & 1.9062 & 1.9270 & 1.9078 \\
\hline \multirow{4}{*}{ 2nd year } & 0.4 & 4 & 4.0793 & 4.0793 & 3.8608 & 3.8133 & 4.0794 & 4.0792 & 4.0796 & 3.8600 & 3.8060 & 4.0795 & 4.0793 & 4.0816 & 3.8600 & 3.8056 & 3.8269 & 3.8097 \\
\hline & & 16 & 3.7747 & 3.7748 & 1.9380 & 1.9354 & 3.7751 & 3.7754 & 3.7756 & 1.9375 & 1.9346 & 3.7752 & 3.7755 & 3.7759 & 1.9376 & 1.9345 & 1.9282 & 1.9255 \\
\hline & 0.8 & 4 & 4.4390 & 4.4391 & 4.2819 & 4.2224 & 4.4388 & 4.4386 & 4.4209 & 4.2783 & 4.1971 & 4.4396 & 4.4396 & 4.4105 & 4.2777 & 4.1952 & 4.2168 & 4.2313 \\
\hline & & 16 & 3.8696 & 3.8697 & 2.1223 & 2.1191 & 3.8716 & 3.8714 & 3.8791 & 2.1201 & 2.1157 & 3.8718 & 3.8717 & 3.8821 & 2.1199 & 2.1149 & 2.1374 & 2.1270 \\
\hline \multirow{4}{*}{ 3rd year } & 0.4 & 4 & 4.2357 & 4.2358 & 4.0121 & 3.9644 & 4.2358 & 4.2358 & 4.2367 & 4.0111 & 3.9563 & 4.2360 & 4.2359 & 4.2393 & 4.0111 & 3.9560 & 3.9785 & 3.9661 \\
\hline & & 16 & 3.8526 & 3.8527 & 2.0109 & 2.0084 & 3.8531 & 3.8534 & 3.8521 & 2.0104 & 2.0074 & 3.8531 & 3.8535 & 3.8537 & 2.0104 & 2.0074 & 2.0076 & 2.0047 \\
\hline & 0.8 & 4 & 4.6176 & 4.6177 & 4.4527 & 4.3926 & 4.6176 & 4.6175 & 4.5966 & 4.4490 & 4.3684 & 4.6184 & 4.6184 & 4.5887 & 4.4483 & 4.3652 & 4.3835 & 4.3981 \\
\hline & & 16 & 3.9613 & 3.9614 & 2.2116 & 2.2084 & 3.9636 & 3.9634 & 3.9673 & 2.2095 & 2.2054 & 3.9638 & 3.9636 & 3.9692 & 2.2094 & 2.2045 & 2.2194 & 2.2168 \\
\hline \multirow{4}{*}{ 4th year } & 0.4 & 4 & 4.3113 & 4.3114 & 4.0834 & 4.0354 & 4.3110 & 4.3111 & 4.3131 & 4.0823 & 4.0263 & 4.3112 & 4.3112 & 4.3161 & 4.0823 & 4.0263 & 4.0608 & 4.0475 \\
\hline & & 16 & 3.8901 & 3.8902 & 2.0500 & 2.0474 & 3.8905 & 3.8908 & 3.8901 & 2.0494 & 2.0464 & 3.8906 & 3.8909 & 3.8917 & 2.0494 & 2.0463 & 2.0465 & 2.0482 \\
\hline & 0.8 & 4 & 4.7133 & 4.7133 & 4.5470 & 4.4856 & 4.7135 & 4.7134 & 4.6870 & 4.5433 & 4.4613 & 4.7146 & 4.7144 & 4.6837 & 4.5428 & 4.4581 & 4.4617 & 4.4901 \\
\hline & & 16 & 4.0100 & 4.0101 & 2.2659 & 2.2627 & 4.0122 & 4.0121 & 4.0134 & 2.2642 & 2.2598 & 4.0123 & 4.0122 & 4.0152 & 2.2639 & 2.2590 & 2.2619 & 2.2631 \\
\hline \multirow{4}{*}{ 5th year } & 0.4 & 4 & 4.3637 & 4.3638 & 4.1367 & 4.0876 & 4.3635 & 4.3635 & 4.3653 & 4.1357 & 4.0786 & 4.3637 & 4.3637 & 4.3695 & 4.1357 & 4.0786 & 4.1094 & 4.0975 \\
\hline & & 16 & 3.9122 & 3.9124 & 2.0748 & 2.0722 & 3.9126 & 3.9129 & 3.9147 & 2.0743 & 2.0712 & 3.9127 & 3.9131 & 3.9147 & 2.0742 & 2.0711 & 2.0729 & 2.0752 \\
\hline & 0.8 & 4 & 4.7697 & 4.7698 & 4.6004 & 4.5394 & 4.7702 & 4.7700 & 4.7457 & 4.5967 & 4.5160 & 4.7713 & 4.7712 & 4.7428 & 4.5963 & 4.5125 & 4.5223 & 4.5371 \\
\hline & & 16 & 4.0405 & 4.0405 & 2.2956 & 2.2926 & 4.0426 & 4.0425 & 4.0396 & 2.2937 & 2.2898 & 4.0428 & 4.0427 & 4.0411 & 2.2934 & 2.2889 & 2.2890 & 2.2901 \\
\hline \multirow{4}{*}{ Average } & 0.4 & 4 & 4.1321 & 4.1321 & 3.9129 & 3.8653 & 4.1320 & 4.1319 & 4.1331 & 3.9120 & 3.8573 & 4.1322 & 4.1320 & 4.1347 & 3.9120 & 3.8570 & 3.8817 & 3.8717 \\
\hline & & 16 & 3.7976 & 3.7977 & 1.9644 & 1.9618 & 3.7979 & 3.7982 & 3.7986 & 1.9639 & 1.9609 & 3.7980 & 3.7983 & 3.7986 & 1.9639 & 1.9608 & 1.9599 & 1.9572 \\
\hline & 0.8 & 4 & 4.5053 & 4.5054 & 4.3466 & 4.2861 & 4.5051 & 4.5050 & 4.4876 & 4.3431 & 4.2616 & 4.5059 & 4.5059 & 4.4805 & 4.3426 & 4.2589 & 4.2752 & 4.2956 \\
\hline & & 16 & 3.9036 & 3.9036 & 2.1614 & 2.1584 & 3.9056 & 3.9054 & 3.9046 & 2.1594 & 2.1555 & 3.9058 & 3.9055 & 3.9079 & 2.1592 & 2.1547 & 2.1669 & 2.1610 \\
\hline
\end{tabular}


Table 3 - Forecasts RMSE - $(\mathrm{N}, \mathrm{T})=(50,10)$, SAR data generating process for $\phi, \mathrm{W}(5,5), 1000$ replications

\begin{tabular}{|c|c|c|c|c|c|c|c|c|c|c|c|c|c|c|c|c|c|c|}
\hline & \multicolumn{18}{|c|}{ Estimators } \\
\hline & \multirow[b]{2}{*}{$\rho$} & \multirow[b]{2}{*}{$\sigma_{\mu}^{2}$} & \multirow{2}{*}{$\begin{array}{c}\text { Pooled } \\
\text { OLS }\end{array}$} & \multirow{2}{*}{$\begin{array}{c}\text { Av. hetero. } \\
\text { OLS }\end{array}$} & \multirow{2}{*}{ FE } & \multirow{2}{*}{$\mathrm{RE}$} & \multirow{2}{*}{$\begin{array}{c}\text { Pooled SAR } \\
\text { MLE }\end{array}$} & \multicolumn{2}{|c|}{ Av. hetero. SAR } & \multirow{2}{*}{$\begin{array}{c}\text { FE-SAR } \\
\text { MLE }\end{array}$} & \multirow{2}{*}{$\begin{array}{c}\text { RE-SAR } \\
\text { MLE }\end{array}$} & \multirow{2}{*}{$\begin{array}{c}\text { Pooled SMA } \\
\text { MLE }\end{array}$} & \multicolumn{2}{|c|}{ Av. hetero. SMA } & \multirow{2}{*}{$\begin{array}{c}\text { FE-SMA } \\
\text { MLE }\end{array}$} & \multirow{2}{*}{$\begin{array}{c}\text { RE-SMA } \\
\text { MLE }\end{array}$} & \multirow{2}{*}{$\begin{array}{c}\text { SAR-RE } \\
\text { GM }\end{array}$} & \multirow{2}{*}{$\begin{array}{c}\text { SMA-RE } \\
\text { GM }\end{array}$} \\
\hline & & & & & & & & MLE & GM & & & & MLE & GM & & & & \\
\hline \multirow{4}{*}{ 1st year } & 0.4 & 4 & 3.6604 & 3.6604 & 3.4537 & 3.4118 & 3.6600 & 3.6601 & 3.6448 & 3.4535 & 3.4095 & 3.6602 & 3.6603 & 3.6338 & 3.4536 & 3.4095 & 3.4415 & 3.4417 \\
\hline & & 16 & 3.5736 & 3.5735 & 1.7414 & 1.7405 & 3.5737 & 3.5739 & 3.5697 & 1.7410 & 1.7402 & 3.5736 & 3.5739 & 3.5671 & 1.7411 & 1.7403 & 1.7351 & 1.7342 \\
\hline & 0.8 & 4 & 4.9150 & 4.9149 & 4.8055 & 4.7733 & 4.9133 & 4.8926 & 4.8984 & 4.8040 & 4.7355 & 4.9135 & 4.8926 & 4.9076 & 4.8040 & 4.7365 & 4.7109 & 4.7822 \\
\hline & & 16 & 3.9279 & 3.9279 & 2.4155 & 2.4138 & 3.9283 & 3.9272 & 3.8975 & 2.4131 & 2.4063 & 3.9284 & 3.9270 & 3.9042 & 2.4133 & 2.4080 & 2.3947 & 2.3975 \\
\hline \multirow{4}{*}{ 2nd year } & 0.4 & 4 & 4.0515 & 4.0516 & 3.8391 & 3.7896 & 4.0515 & 4.0515 & 4.0529 & 3.8386 & 3.7868 & 4.0515 & 4.0516 & 4.0498 & 3.8386 & 3.7868 & 3.8221 & 3.8177 \\
\hline & & 16 & 3.7783 & 3.7784 & 1.9310 & 1.9294 & 3.7785 & 3.7786 & 3.7817 & 1.9307 & 1.9290 & 3.7786 & 3.7790 & 3.7805 & 1.9307 & 1.9291 & 1.9233 & 1.9236 \\
\hline & 0.8 & 4 & 5.4516 & 5.4517 & 5.3368 & 5.2966 & 5.4509 & 5.4281 & 5.4571 & 5.3352 & 5.2602 & 5.4510 & 5.4283 & 5.4597 & 5.3351 & 5.2595 & 5.2384 & 5.3148 \\
\hline & & 16 & 4.2189 & 4.2188 & 2.6745 & 2.6715 & 4.2195 & 4.2180 & 4.2021 & 2.6725 & 2.6625 & 4.2198 & 4.2181 & 4.1977 & 2.6725 & 2.6652 & 2.6551 & 2.6764 \\
\hline \multirow{4}{*}{ 3rd year } & 0.4 & 4 & 4.2132 & 4.2133 & 3.9946 & 3.9444 & 4.2133 & 4.2134 & 4.2197 & 3.9941 & 3.9419 & 4.2133 & 4.2135 & 4.2203 & 3.9942 & 3.9419 & 3.9698 & 3.9781 \\
\hline & & 16 & 3.8499 & 3.8500 & 2.0047 & 2.0029 & 3.8500 & 3.8503 & 3.8582 & 2.0045 & 2.0025 & 3.8501 & 3.8506 & 3.8556 & 2.0045 & 2.0025 & 2.0018 & 1.9992 \\
\hline & 0.8 & 4 & 5.6484 & 5.6484 & 5.5355 & 5.4903 & 5.6473 & 5.6280 & 5.6924 & 5.5331 & 5.4516 & 5.6475 & 5.6282 & 5.6855 & 5.5331 & 5.4521 & 5.4781 & 5.5263 \\
\hline & & 16 & 4.3224 & 4.3224 & 2.7734 & 2.7701 & 4.3232 & 4.3219 & 4.3141 & 2.7716 & 2.7613 & 4.3235 & 4.3221 & 4.3130 & 2.7717 & 2.7640 & 2.7746 & 2.7792 \\
\hline \multirow{4}{*}{ 4th year } & 0.4 & 4 & 4.3083 & 4.3083 & 4.0871 & 4.0372 & 4.3086 & 4.3085 & 4.3133 & 4.0867 & 4.0341 & 4.3085 & 4.3087 & 4.3118 & 4.0867 & 4.0342 & 4.0471 & 4.0522 \\
\hline & & 16 & 3.8902 & 3.8902 & 2.0461 & 2.0442 & 3.8903 & 3.8904 & 3.8991 & 2.0458 & 2.0437 & 3.8904 & 3.8908 & 3.8944 & 2.0458 & 2.0437 & 2.0420 & 2.0440 \\
\hline & 0.8 & 4 & 5.7632 & 5.7632 & 5.6516 & 5.6042 & 5.7617 & 5.7412 & 5.7872 & 5.6492 & 5.5624 & 5.7619 & 5.7413 & 5.7905 & 5.6492 & 5.5644 & 5.5835 & 5.6212 \\
\hline & & 16 & 4.3837 & 4.3836 & 2.8346 & 2.8315 & 4.3844 & 4.3831 & 4.3727 & 2.8325 & 2.8224 & 4.3847 & 4.3833 & 4.3731 & 2.8326 & 2.8250 & 2.8343 & 2.8335 \\
\hline \multirow{4}{*}{ 5th year } & 0.4 & 4 & 4.3621 & 4.3621 & 4.1403 & 4.0901 & 4.3623 & 4.3622 & 4.3606 & 4.1399 & 4.0869 & 4.3622 & 4.3624 & 4.3587 & 4.1399 & 4.0870 & 4.0913 & 4.1018 \\
\hline & & 16 & 3.9133 & 3.9134 & 2.0714 & 2.0695 & 3.9135 & 3.9137 & 3.9247 & 2.0712 & 2.0691 & 3.9136 & 3.9141 & 3.9197 & 2.0712 & 2.0691 & 2.0665 & 2.0674 \\
\hline & 0.8 & 4 & 5.8382 & 5.8382 & 5.7313 & 5.6808 & 5.8371 & 5.8162 & 5.8620 & 5.7293 & 5.6378 & 5.8372 & 5.8164 & 5.8640 & 5.7292 & 5.6407 & 5.6510 & 5.7074 \\
\hline & & 16 & 4.4187 & 4.4186 & 2.8668 & 2.8640 & 4.4195 & 4.4182 & 4.4019 & 2.8648 & 2.8551 & 4.4198 & 4.4184 & 4.3993 & 2.8649 & 2.8576 & 2.8702 & 2.8755 \\
\hline \multirow{4}{*}{ Average } & 0.4 & 4 & 4.1191 & 4.1191 & 3.9030 & 3.8546 & 4.1191 & 4.1191 & 4.1182 & 3.9025 & 3.8518 & 4.1191 & 4.1193 & 4.1149 & 3.9026 & 3.8519 & 3.8744 & 3.8783 \\
\hline & & 16 & 3.8010 & 3.8011 & 1.9589 & 1.9573 & 3.8012 & 3.8014 & 3.8067 & 1.9586 & 1.9569 & 3.8012 & 3.8017 & 3.8035 & 1.9587 & 1.9569 & 1.9537 & 1.9537 \\
\hline & 0.8 & 4 & 5.5233 & 5.5233 & 5.4121 & 5.3690 & 5.5221 & 5.5012 & 5.5394 & 5.4102 & 5.3295 & 5.5222 & 5.5014 & 5.5414 & 5.4101 & 5.3306 & 5.3324 & 5.3904 \\
\hline & & 16 & 4.2543 & 4.2542 & 2.7129 & 2.7102 & 4.2550 & 4.2537 & 4.2376 & 2.7109 & 2.7015 & 4.2552 & 4.2538 & 4.2375 & 2.7110 & 2.7040 & 2.7058 & 2.7124 \\
\hline
\end{tabular}


Table 4 - Forecasts RMSE - $(\mathrm{N}, \mathrm{T})=(\mathbf{5 0 , 1 0 )}$, SMA data generating process for $\phi, W(5,5), 1000$ replications

\begin{tabular}{|c|c|c|c|c|c|c|c|c|c|c|c|c|c|c|c|c|c|c|}
\hline & \multicolumn{18}{|c|}{ Estimators } \\
\hline & \multirow[b]{2}{*}{$\lambda$} & \multirow[b]{2}{*}{$\sigma_{\mu}^{2}$} & \multirow{2}{*}{$\begin{array}{c}\text { Pooled } \\
\text { OLS }\end{array}$} & \multirow{2}{*}{$\begin{array}{l}\text { Av. hetero. } \\
\text { OLS }\end{array}$} & \multirow{2}{*}{ FE } & \multirow{2}{*}{$\mathrm{RE}$} & \multirow{2}{*}{$\begin{array}{c}\text { Pooled SAR } \\
\text { MLE }\end{array}$} & \multicolumn{2}{|c|}{ Av. hetero. SAR } & \multirow{2}{*}{$\begin{array}{c}\text { FE-SAR } \\
\text { MLE }\end{array}$} & \multirow{2}{*}{$\begin{array}{c}\text { RE-SAR } \\
\text { MLE }\end{array}$} & \multirow{2}{*}{$\begin{array}{c}\text { Pooled SMA } \\
\text { MLE }\end{array}$} & \multicolumn{2}{|c|}{ Av. hetero. SMA } & \multirow{2}{*}{$\begin{array}{c}\text { FE-SMA } \\
\text { MLE }\end{array}$} & \multirow{2}{*}{$\begin{array}{c}\text { RE-SMA } \\
\text { MLE }\end{array}$} & \multirow{2}{*}{$\begin{array}{c}\text { SAR-RE } \\
\text { GM }\end{array}$} & \multirow{2}{*}{$\begin{array}{c}\text { SMA-RE } \\
\text { GM }\end{array}$} \\
\hline & & & & & & & & MLE & GM & & & & MLE & GM & & & & \\
\hline \multirow{4}{*}{ 1st year } & 0.4 & 4 & 3.5909 & 3.5909 & 3.3764 & 3.3363 & 3.5911 & 3.5912 & 3.5823 & 3.3759 & 3.3356 & 3.5911 & 3.5911 & 3.5859 & 3.3759 & 3.3354 & 3.3417 & 3.3338 \\
\hline & & 16 & 3.5114 & 3.5116 & 1.6868 & 1.6846 & 3.5115 & 3.5116 & 3.5249 & 1.6867 & 1.6843 & 3.5115 & 3.5121 & 3.5175 & 1.6867 & 1.6843 & 1.6906 & 1.6851 \\
\hline & 0.8 & 4 & 3.6763 & 3.6763 & 3.4731 & 3.4312 & 3.6759 & 3.6761 & 3.6593 & 3.4724 & 3.4280 & 3.6760 & 3.6763 & 3.6546 & 3.4722 & 3.4275 & 3.4035 & 3.3943 \\
\hline & & 16 & 3.5299 & 3.5300 & 1.7293 & 1.7273 & 3.5300 & 3.5304 & 3.5553 & 1.7291 & 1.7269 & 3.5301 & 3.5306 & 3.5662 & 1.7290 & 1.7267 & 1.7231 & 1.7248 \\
\hline \multirow{4}{*}{ 2nd year } & 0.4 & 4 & 3.9719 & 3.9720 & 3.7426 & 3.6993 & 3.9721 & 3.9724 & 3.9858 & 3.7424 & 3.6988 & 3.9721 & 3.9726 & 3.9829 & 3.7424 & 3.6985 & 3.7173 & 3.7026 \\
\hline & & 16 & 3.7285 & 3.7287 & 1.8800 & 1.8778 & 3.7289 & 3.7291 & 3.7246 & 1.8798 & 1.8774 & 3.7289 & 3.7295 & 3.7237 & 1.8798 & 1.8774 & 1.8757 & 1.8718 \\
\hline & 0.8 & 4 & 4.0662 & 4.0662 & 3.8506 & 3.8034 & 4.0658 & 4.0659 & 4.0556 & 3.8497 & 3.7987 & 4.0659 & 4.0660 & 4.0490 & 3.8496 & 3.7984 & 3.7954 & 3.7802 \\
\hline & & 16 & 3.7328 & 3.7328 & 1.9132 & 1.9106 & 3.7330 & 3.7333 & 3.7692 & 1.9130 & 1.9100 & 3.7331 & 3.7335 & 3.7823 & 1.9129 & 1.9101 & 1.9116 & 1.9099 \\
\hline \multirow{4}{*}{ 3rd year } & 0.4 & 4 & 4.1258 & 4.1258 & 3.8950 & 3.8495 & 4.1259 & 4.1262 & 4.1356 & 3.8946 & 3.8482 & 4.1259 & 4.1264 & 4.1315 & 3.8946 & 3.8480 & 3.8544 & 3.8491 \\
\hline & & 16 & 3.8057 & 3.8059 & 1.9534 & 1.9513 & 3.8059 & 3.8061 & 3.8035 & 1.9533 & 1.9510 & 3.8060 & 3.8065 & 3.8018 & 1.9533 & 1.9510 & 1.9528 & 1.9464 \\
\hline & 0.8 & 4 & 4.2227 & 4.2227 & 3.9958 & 3.9493 & 4.2222 & 4.2224 & 4.2096 & 3.9949 & 3.9452 & 4.2223 & 4.2226 & 4.2038 & 3.9947 & 3.9447 & 3.9422 & 3.9333 \\
\hline & & 16 & 3.8127 & 3.8128 & 1.9925 & 1.9899 & 3.8129 & 3.8131 & 3.8410 & 1.9923 & 1.9896 & 3.8130 & 3.8134 & 3.8527 & 1.9923 & 1.9896 & 1.9869 & 1.9913 \\
\hline \multirow{4}{*}{4 th year } & 0.4 & 4 & 4.2050 & 4.2051 & 3.9729 & 3.9270 & 4.2050 & 4.2053 & 4.2140 & 3.9726 & 3.9258 & 4.2050 & 4.2055 & 4.2135 & 3.9726 & 3.9255 & 3.9288 & 3.9275 \\
\hline & & 16 & 3.8465 & 3.8466 & 1.9921 & 1.9902 & 3.8467 & 3.8469 & 3.8420 & 1.9919 & 1.9898 & 3.8467 & 3.8473 & 3.8395 & 1.9919 & 1.9899 & 1.9900 & 1.9894 \\
\hline & 0.8 & 4 & 4.3004 & 4.3004 & 4.0741 & 4.0261 & 4.2999 & 4.3001 & 4.2914 & 4.0734 & 4.0214 & 4.3000 & 4.3002 & 4.2846 & 4.0732 & 4.0209 & 4.0191 & 4.0143 \\
\hline & & 16 & 3.8530 & 3.8531 & 2.0306 & 2.0282 & 3.8531 & 3.8533 & 3.8774 & 2.0304 & 2.0280 & 3.8532 & 3.8536 & 3.8810 & 2.0303 & 2.0279 & 2.0313 & 2.0293 \\
\hline \multirow{4}{*}{ 5th year } & 0.4 & 4 & 4.2560 & 4.2561 & 4.0203 & 3.9746 & 4.2560 & 4.2562 & 4.2663 & 4.0200 & 3.9735 & 4.2560 & 4.2564 & 4.2663 & 4.0200 & 3.9733 & 3.9762 & 3.9787 \\
\hline & & 16 & 3.8694 & 3.8696 & 2.0158 & 2.0139 & 3.8697 & 3.8700 & 3.8634 & 2.0157 & 2.0136 & 3.8697 & 3.8704 & 3.8610 & 2.0157 & 2.0136 & 2.0141 & 2.0161 \\
\hline & 0.8 & 4 & 4.3474 & 4.3474 & 4.1229 & 4.0736 & 4.3469 & 4.3472 & 4.3447 & 4.1222 & 4.0683 & 4.3470 & 4.3473 & 4.3401 & 4.1221 & 4.0678 & 4.0724 & 4.0629 \\
\hline & & 16 & 3.8766 & 3.8767 & 2.0576 & 2.0551 & 3.8767 & 3.8769 & 3.8999 & 2.0573 & 2.0548 & 3.8768 & 3.8771 & 3.9069 & 2.0572 & 2.0547 & 2.0545 & 2.0553 \\
\hline \multirow{4}{*}{ Average } & 0.4 & 4 & 4.0299 & 4.0300 & 3.8014 & 3.7573 & 4.0300 & 4.0303 & 4.0368 & 3.8011 & 3.7564 & 4.0300 & 4.0304 & 4.0360 & 3.8011 & 3.7562 & 3.7637 & 3.7583 \\
\hline & & 16 & 3.7523 & 3.7525 & 1.9056 & 1.9035 & 3.7525 & 3.7527 & 3.7517 & 1.9055 & 1.9032 & 3.7525 & 3.7532 & 3.7487 & 1.9055 & 1.9032 & 1.9046 & 1.9018 \\
\hline & 0.8 & 4 & 4.1226 & 4.1226 & 3.9033 & 3.8567 & 4.1222 & 4.1223 & 4.1121 & 3.9025 & 3.8523 & 4.1222 & 4.1225 & 4.1064 & 3.9024 & 3.8519 & 3.8465 & 3.8370 \\
\hline & & 16 & 3.7610 & 3.7611 & 1.9446 & 1.9422 & 3.7611 & 3.7614 & 3.7885 & 1.9444 & 1.9419 & 3.7612 & 3.7616 & 3.7989 & 1.9444 & 1.9418 & 1.9415 & 1.9421 \\
\hline
\end{tabular}


Table 5 - Forecasts RMSE - $(\mathrm{N}, \mathrm{T})=(50,20)$, SAR data generating process for $\phi, W(1,1), 1000$ replications

\begin{tabular}{|c|c|c|c|c|c|c|c|c|c|c|c|c|c|c|c|c|c|c|}
\hline & \multicolumn{18}{|c|}{ Estimators } \\
\hline & \multirow[b]{2}{*}{$\rho$} & \multirow[b]{2}{*}{$\sigma_{\mu}^{2}$} & \multirow{2}{*}{$\begin{array}{c}\text { Pooled } \\
\text { OLS }\end{array}$} & \multirow{2}{*}{$\begin{array}{c}\text { Av. hetero. } \\
\text { OLS }\end{array}$} & \multirow{2}{*}{ FE } & \multirow{2}{*}{ RE } & \multirow{2}{*}{$\begin{array}{c}\text { Pooled SAR } \\
\text { MLE }\end{array}$} & \multicolumn{2}{|c|}{ Av. hetero. SAR } & \multirow{2}{*}{$\begin{array}{c}\text { FE-SAR } \\
\text { MLE }\end{array}$} & \multirow{2}{*}{$\begin{array}{c}\text { RE-SAR } \\
\text { MLE }\end{array}$} & \multirow{2}{*}{$\begin{array}{c}\text { Pooled SMA } \\
\text { MLE }\end{array}$} & \multicolumn{2}{|c|}{ Av. hetero. SMA } & \multirow{2}{*}{$\begin{array}{c}\text { FE-SMA } \\
\text { MLE }\end{array}$} & \multirow{2}{*}{$\begin{array}{c}\text { RE-SMA } \\
\text { MLE }\end{array}$} & \multirow{2}{*}{$\begin{array}{c}\text { SAR-RE } \\
\text { GM }\end{array}$} & \multirow{2}{*}{$\begin{array}{c}\text { SMA-RE } \\
\text { GM }\end{array}$} \\
\hline & & & & & & & & MLE & GM & & & & MLE & GM & & & & \\
\hline \multirow{4}{*}{ 1st year } & 0.4 & 4 & 3.9511 & 3.9513 & 3.7364 & 3.7155 & 3.9516 & 3.9516 & 3.9631 & 3.7358 & 3.7105 & 3.9516 & 3.9517 & 3.9672 & 3.7358 & 3.7096 & 3.7289 & 3.7116 \\
\hline & & 16 & 3.6164 & 3.6164 & 1.8633 & 1.8625 & 3.6180 & 3.6180 & 3.6429 & 1.8629 & 1.8618 & 3.6182 & 3.6183 & 3.6441 & 1.8629 & 1.8618 & 1.8654 & 1.8654 \\
\hline & 0.8 & 4 & 7.0636 & 7.0637 & 7.0399 & 6.9797 & 7.0634 & 7.0543 & 7.1286 & 7.0359 & 6.9436 & 7.0642 & 7.0551 & 7.1390 & 7.0356 & 6.9442 & 6.9870 & 6.9751 \\
\hline & & 16 & 4.6604 & 4.6608 & 3.5080 & 3.5046 & 4.6610 & 4.6607 & 4.7277 & 3.5066 & 3.4980 & 4.6604 & 4.6601 & 4.7194 & 3.5067 & 3.4997 & 3.4914 & 3.4981 \\
\hline \multirow{4}{*}{ 2nd year } & 0.4 & 4 & 4.4075 & 4.4079 & 4.1572 & 4.1384 & 4.4081 & 4.4083 & 4.3916 & 4.1563 & 4.1335 & 4.4081 & 4.4084 & 4.3948 & 4.1563 & 4.1329 & 4.1372 & 4.1361 \\
\hline & & 16 & 3.8526 & 3.8526 & 2.0675 & 2.0667 & 3.8538 & 3.8539 & 3.8684 & 2.0672 & 2.0662 & 3.8539 & 3.8541 & 3.8755 & 2.0673 & 2.0663 & 2.0692 & 2.0659 \\
\hline & 0.8 & 4 & 7.8524 & 7.8523 & 7.8121 & 7.7512 & 7.8511 & 7.8442 & 7.8893 & 7.8082 & 7.7158 & 7.8530 & 7.8459 & 7.9029 & 7.8083 & 7.7174 & 7.7551 & 7.7475 \\
\hline & & 16 & 5.1228 & 5.1230 & 3.9200 & 3.9160 & 5.1233 & 5.1228 & 5.1328 & 3.9180 & 3.9080 & 5.1233 & 5.1228 & 5.1272 & 3.9180 & 3.9100 & 3.8881 & 3.9055 \\
\hline \multirow{4}{*}{ 3rd year } & 0.4 & 4 & 4.5841 & 4.5843 & 4.3239 & 4.3050 & 4.5846 & 4.5847 & 4.5668 & 4.3234 & 4.2998 & 4.5847 & 4.5849 & 4.5692 & 4.3234 & 4.2997 & 4.3076 & 4.3034 \\
\hline & & 16 & 3.9438 & 3.9438 & 2.1507 & 2.1500 & 3.9446 & 3.9447 & 3.9571 & 2.1504 & 2.1495 & 3.9447 & 3.9448 & 3.9611 & 2.1504 & 2.1495 & 2.1549 & 2.1467 \\
\hline & 0.8 & 4 & 8.1797 & 8.1796 & 8.1425 & 8.0788 & 8.1789 & 8.1712 & 8.1870 & 8.1380 & 8.0444 & 8.1804 & 8.1727 & 8.1969 & 8.1380 & 8.0442 & 8.1139 & 8.0629 \\
\hline & & 16 & 5.2836 & 5.2838 & 4.0774 & 4.0722 & 5.2842 & 5.2837 & 5.3024 & 4.0753 & 4.0618 & 5.2844 & 5.2839 & 5.2963 & 4.0754 & 4.0656 & 4.0413 & 4.0582 \\
\hline \multirow{4}{*}{ 4th year } & 0.4 & 4 & 4.6767 & 4.6769 & 4.4123 & 4.3931 & 4.6772 & 4.6773 & 4.6529 & 4.4118 & 4.3881 & 4.6773 & 4.6775 & 4.6563 & 4.4118 & 4.3879 & 4.3893 & 4.3832 \\
\hline & & 16 & 3.9904 & 3.9904 & 2.1964 & 2.1957 & 3.9916 & 3.9916 & 4.0038 & 2.1961 & 2.1953 & 3.9917 & 3.9918 & 4.0078 & 2.1961 & 2.1953 & 2.1976 & 2.1898 \\
\hline & 0.8 & 4 & 8.3518 & 8.3519 & 8.3136 & 8.2480 & 8.3510 & 8.3435 & 8.3496 & 8.3097 & 8.2129 & 8.3527 & 8.3452 & 8.3546 & 8.3097 & 8.2123 & 8.2705 & 8.2339 \\
\hline & & 16 & 5.3737 & 5.3739 & 4.1635 & 4.1581 & 5.3748 & 5.3741 & 5.3871 & 4.1614 & 4.1466 & 5.3750 & 5.3743 & 5.3838 & 4.1615 & 4.1512 & 4.1180 & 4.1433 \\
\hline \multirow{4}{*}{ 5th year } & 0.4 & 4 & 4.7296 & 4.7298 & 4.4640 & 4.4440 & 4.7300 & 4.7302 & 4.7138 & 4.4635 & 4.4388 & 4.7302 & 4.7303 & 4.7164 & 4.4635 & 4.4386 & 4.4428 & 4.4382 \\
\hline & & 16 & 4.0171 & 4.0171 & 2.2227 & 2.2221 & 4.0185 & 4.0185 & 4.0283 & 2.2224 & 2.2216 & 4.0186 & 4.0186 & 4.0318 & 2.2224 & 2.2216 & 2.2232 & 2.2189 \\
\hline & 0.8 & 4 & 8.4459 & 8.4460 & 8.4041 & 8.3400 & 8.4451 & 8.4372 & 8.4425 & 8.4005 & 8.3036 & 8.4469 & 8.4390 & 8.4449 & 8.4006 & 8.3035 & 8.3642 & 8.3287 \\
\hline & & 16 & 5.4261 & 5.4263 & 4.2084 & 4.2034 & 5.4281 & 5.4273 & 5.4429 & 4.2062 & 4.1923 & 5.4284 & 5.4276 & 5.4431 & 4.2063 & 4.1964 & 4.1699 & 4.1907 \\
\hline \multirow{4}{*}{ Average } & 0.4 & 4 & 4.4698 & 4.4700 & 4.2188 & 4.1992 & 4.4703 & 4.4704 & 4.4576 & 4.2182 & 4.1941 & 4.4704 & 4.4706 & 4.4604 & 4.2182 & 4.1937 & 4.2012 & 4.1945 \\
\hline & & 16 & 3.8840 & 3.8841 & 2.1001 & 2.0994 & 3.8853 & 3.8853 & 3.9001 & 2.0998 & 2.0989 & 3.8854 & 3.8855 & 3.9041 & 2.0998 & 2.0989 & 2.1021 & 2.0974 \\
\hline & 0.8 & 4 & 7.9787 & 7.9787 & 7.9424 & 7.8796 & 7.9779 & 7.9701 & 7.9994 & 7.9385 & 7.8441 & 7.9794 & 7.9716 & 8.0077 & 7.9384 & 7.8443 & 7.8981 & 7.8696 \\
\hline & & 16 & 5.1733 & 5.1736 & 3.9755 & 3.9709 & 5.1743 & 5.1737 & 5.1986 & 3.9735 & 3.9614 & 5.1743 & 5.1737 & 5.1940 & 3.9736 & 3.9646 & 3.9417 & 3.9592 \\
\hline
\end{tabular}


Table 6 - Forecasts RMSE - $(\mathrm{N}, \mathrm{T})=(50,20)$, SMA data generating process for $\phi, W(1,1), 1000$ replications

\begin{tabular}{|c|c|c|c|c|c|c|c|c|c|c|c|c|c|c|c|c|c|c|}
\hline & \multicolumn{18}{|c|}{ Estimators } \\
\hline & \multirow[b]{2}{*}{$\lambda$} & \multirow[b]{2}{*}{$\sigma_{\mu}^{2}$} & \multirow{2}{*}{$\begin{array}{c}\text { Pooled } \\
\text { OLS }\end{array}$} & \multirow{2}{*}{$\begin{array}{c}\text { Av. hetero. } \\
\text { OLS }\end{array}$} & \multirow{2}{*}{ FE } & \multirow{2}{*}{$\mathrm{RE}$} & \multirow{2}{*}{$\begin{array}{c}\text { Pooled SAR } \\
\text { MLE }\end{array}$} & \multicolumn{2}{|c|}{ Av. hetero. SAR } & \multirow{2}{*}{$\begin{array}{c}\text { FE-SAR } \\
\text { MLE }\end{array}$} & \multirow{2}{*}{$\begin{array}{c}\text { RE-SAR } \\
\text { MLE }\end{array}$} & \multirow{2}{*}{$\begin{array}{c}\text { Pooled SMA } \\
\text { MLE }\end{array}$} & \multicolumn{2}{|c|}{ Av. hetero. SMA } & \multirow{2}{*}{$\begin{array}{c}\text { FE-SMA } \\
\text { MLE }\end{array}$} & \multirow{2}{*}{$\begin{array}{c}\text { RE-SMA } \\
\text { MLE }\end{array}$} & \multirow{2}{*}{$\begin{array}{c}\text { SAR-RE } \\
\text { GM }\end{array}$} & \multirow{2}{*}{$\begin{array}{c}\text { SMA-RE } \\
\text { GM }\end{array}$} \\
\hline & & & & & & & & MLE & GM & & & & MLE & GM & & & & \\
\hline \multirow{4}{*}{ 1st year } & 0.4 & 4 & 3.6699 & 3.6698 & 3.3999 & 3.3863 & 3.6705 & 3.6704 & 3.6873 & 3.3994 & 3.3834 & 3.6706 & 3.6707 & 3.6803 & 3.3994 & 3.3828 & 3.3885 & 3.3517 \\
\hline & & 16 & 3.5573 & 3.5575 & 1.6920 & 1.6915 & 3.5575 & 3.5576 & 3.5501 & 1.6917 & 1.6911 & 3.5574 & 3.5575 & 3.5384 & 1.6917 & 1.6910 & 1.7044 & 1.6870 \\
\hline & 0.8 & 4 & 3.9856 & 3.9856 & 3.7521 & 3.7370 & 3.9854 & 3.9854 & 3.9823 & 3.7505 & 3.7291 & 3.9860 & 3.9858 & 3.9883 & 3.7502 & 3.7282 & 3.7417 & 3.7272 \\
\hline & & 16 & 3.6376 & 3.6376 & 1.8802 & 1.8793 & 3.6387 & 3.6387 & 3.6182 & 1.8795 & 1.8778 & 3.6388 & 3.6389 & 3.6226 & 1.8794 & 1.8777 & 1.8990 & 1.8689 \\
\hline \multirow{4}{*}{ 2nd year } & 0.4 & 4 & 4.0666 & 4.0666 & 3.7765 & 3.7606 & 4.0673 & 4.0673 & 4.0754 & 3.7760 & 3.7571 & 4.0675 & 4.0676 & 4.0721 & 3.7759 & 3.7564 & 3.7690 & 3.7332 \\
\hline & & 16 & 3.7723 & 3.7723 & 1.8861 & 1.8856 & 3.7721 & 3.7724 & 3.7691 & 1.8857 & 1.8851 & 3.7721 & 3.7724 & 3.7580 & 1.8857 & 1.8850 & 1.8916 & 1.8799 \\
\hline & 0.8 & 4 & 4.4240 & 4.4241 & 4.1711 & 4.1538 & 4.4242 & 4.4242 & 4.4219 & 4.1698 & 4.1437 & 4.4251 & 4.4251 & 4.4266 & 4.1695 & 4.1428 & 4.1549 & 4.1537 \\
\hline & & 16 & 3.8756 & 3.8757 & 2.0870 & 2.0860 & 3.8777 & 3.8777 & 3.8650 & 2.0861 & 2.0845 & 3.8779 & 3.8779 & 3.8708 & 2.0860 & 2.0841 & 2.0938 & 2.0732 \\
\hline \multirow{4}{*}{ 3rd year } & 0.4 & 4 & 4.2243 & 4.2243 & 3.9257 & 3.9098 & 4.2250 & 4.2250 & 4.2282 & 3.9252 & 3.9064 & 4.2252 & 4.2254 & 4.2223 & 3.9251 & 3.9058 & 3.9138 & 3.8949 \\
\hline & & 16 & 3.8441 & 3.8443 & 1.9592 & 1.9584 & 3.8440 & 3.8443 & 3.8485 & 1.9589 & 1.9579 & 3.8440 & 3.8443 & 3.8393 & 1.9589 & 1.9579 & 1.9619 & 1.9554 \\
\hline & 0.8 & 4 & 4.5929 & 4.5929 & 4.3315 & 4.3135 & 4.5932 & 4.5932 & 4.5947 & 4.3300 & 4.3043 & 4.5945 & 4.5944 & 4.5975 & 4.3297 & 4.3027 & 4.3126 & 4.3234 \\
\hline & & 16 & 3.9644 & 3.9645 & 2.1704 & 2.1695 & 3.9665 & 3.9665 & 3.9558 & 2.1696 & 2.1682 & 3.9667 & 3.9667 & 3.9574 & 2.1695 & 2.1678 & 2.1776 & 2.1619 \\
\hline \multirow{4}{*}{ 4th year } & 0.4 & 4 & 4.3108 & 4.3109 & 4.0036 & 3.9883 & 4.3114 & 4.3114 & 4.3064 & 4.0030 & 3.9852 & 4.3116 & 4.3117 & 4.3003 & 4.0030 & 3.9846 & 3.9869 & 3.9818 \\
\hline & & 16 & 3.8849 & 3.8850 & 2.0007 & 1.9999 & 3.8847 & 3.8850 & 3.8836 & 2.0005 & 1.9994 & 3.8848 & 3.8850 & 3.8752 & 2.0004 & 1.9994 & 2.0022 & 1.9994 \\
\hline & 0.8 & 4 & 4.6780 & 4.6781 & 4.4134 & 4.3953 & 4.6789 & 4.6789 & 4.6829 & 4.4122 & 4.3857 & 4.6802 & 4.6801 & 4.6843 & 4.4120 & 4.3843 & 4.4054 & 4.4078 \\
\hline & & 16 & 4.0090 & 4.0091 & 2.2137 & 2.2129 & 4.0108 & 4.0108 & 4.0012 & 2.2129 & 2.2117 & 4.0110 & 4.0111 & 4.0032 & 2.2127 & 2.2113 & 2.2213 & 2.2041 \\
\hline \multirow{4}{*}{5 th year } & 0.4 & 4 & 4.3662 & 4.3663 & 4.0529 & 4.0382 & 4.3667 & 4.3666 & 4.3602 & 4.0524 & 4.0357 & 4.3669 & 4.3670 & 4.3537 & 4.0524 & 4.0351 & 4.0411 & 4.0360 \\
\hline & & 16 & 3.9107 & 3.9109 & 2.0252 & 2.0245 & 3.9107 & 3.9110 & 3.9069 & 2.0249 & 2.0240 & 3.9107 & 3.9110 & 3.8986 & 2.0249 & 2.0240 & 2.0274 & 2.0254 \\
\hline & 0.8 & 4 & 4.7359 & 4.7359 & 4.4707 & 4.4520 & 4.7371 & 4.7370 & 4.7369 & 4.4692 & 4.4429 & 4.7385 & 4.7383 & 4.7396 & 4.4689 & 4.4412 & 4.4623 & 4.4588 \\
\hline & & 16 & 4.0418 & 4.0419 & 2.2428 & 2.2421 & 4.0434 & 4.0434 & 4.0313 & 2.2420 & 2.2412 & 4.0436 & 4.0436 & 4.0317 & 2.2418 & 2.2407 & 2.2496 & 2.2321 \\
\hline \multirow{4}{*}{ Average } & 0.4 & 4 & 4.1276 & 4.1276 & 3.8317 & 3.8167 & 4.1282 & 4.1282 & 4.1315 & 3.8312 & 3.8135 & 4.1283 & 4.1285 & 4.1257 & 3.8312 & 3.8129 & 3.8199 & 3.7995 \\
\hline & & 16 & 3.7939 & 3.7940 & 1.9127 & 1.9120 & 3.7938 & 3.7940 & 3.7916 & 1.9124 & 1.9115 & 3.7938 & 3.7940 & 3.7819 & 1.9123 & 1.9115 & 1.9175 & 1.9094 \\
\hline & 0.8 & 4 & 4.4832 & 4.4833 & 4.2277 & 4.2103 & 4.4838 & 4.4837 & 4.4837 & 4.2263 & 4.2012 & 4.4849 & 4.4847 & 4.4873 & 4.2260 & 4.1998 & 4.2154 & 4.2142 \\
\hline & & 16 & 3.9057 & 3.9057 & 2.1188 & 2.1180 & 3.9074 & 3.9074 & 3.8943 & 2.1180 & 2.1167 & 3.9076 & 3.9076 & 3.8971 & 2.1179 & 2.1163 & 2.1282 & 2.1081 \\
\hline
\end{tabular}


Table 7 - Forecasts RMSE - $(\mathrm{N}, \mathrm{T})=(\mathbf{1 0 0 , 1 0}), \mathrm{W}(\mathbf{1 , 1}), 1000$ replications $\rho=\lambda=0.8$ for SAR and SMA data generating processes

\begin{tabular}{|c|c|c|c|c|c|c|c|c|c|c|c|c|c|c|c|c|c|c|}
\hline & \multicolumn{18}{|c|}{ Estimators } \\
\hline & \multirow{2}{*}{$\begin{array}{l}\text { true } \\
\text { DGP }\end{array}$} & \multirow[b]{2}{*}{$\sigma_{\mu}^{2}$} & \multirow{2}{*}{$\begin{array}{c}\text { Pooled } \\
\text { OLS }\end{array}$} & \multirow{2}{*}{$\begin{array}{c}\text { Av. hetero. } \\
\text { OLS }\end{array}$} & \multirow{2}{*}{$\mathrm{FE}$} & \multirow{2}{*}{$\mathrm{RE}$} & \multirow{2}{*}{$\begin{array}{c}\text { Pooled SAR } \\
\text { MLE }\end{array}$} & \multicolumn{2}{|c|}{ Av. hetero. SAR } & \multirow{2}{*}{$\begin{array}{c}\text { FE-SAR } \\
\text { MLE }\end{array}$} & \multirow{2}{*}{$\begin{array}{c}\text { RE-SAR } \\
\text { MLE }\end{array}$} & \multirow{2}{*}{$\begin{array}{c}\text { Pooled SMA } \\
\text { MLE }\end{array}$} & \multicolumn{2}{|c|}{ Av. hetero. SMA } & \multirow{2}{*}{$\begin{array}{c}\text { FE-SMA } \\
\text { MLE }\end{array}$} & \multirow{2}{*}{$\begin{array}{c}\text { RE-SMA } \\
\text { MLE }\end{array}$} & \multirow{2}{*}{$\begin{array}{c}\text { SAR-RE } \\
\text { GM }\end{array}$} & \multirow{2}{*}{$\begin{array}{c}\text { SMA-RE } \\
\text { GM }\end{array}$} \\
\hline & & & & & & & & MLE & GM & & & & MLE & GM & & & & \\
\hline \multirow{4}{*}{1 st year } & \multirow{2}{*}{ SAR } & 4 & 6.9985 & 6.9985 & 7.1226 & 6.9431 & 6.9975 & 6.9935 & 7.1114 & 7.1190 & 6.8901 & 6.9986 & 6.9947 & 7.0931 & 7.1193 & 6.8938 & 7.0744 & 7.0337 \\
\hline & & 16 & 4.6503 & 4.6503 & 3.5892 & 3.5704 & 4.6506 & 4.6505 & 4.6766 & 3.5874 & 3.5416 & 4.6506 & 4.6505 & 4.4448 & 3.5873 & 3.5529 & 3.5902 & 3.5771 \\
\hline & \multirow{2}{*}{ SMA } & 4 & 4.0103 & 4.0102 & 3.8592 & 3.8002 & 4.0100 & 4.0100 & 4.0062 & 3.8581 & 3.7799 & 4.0108 & 4.0107 & 3.9849 & 3.8580 & 3.7780 & 3.7920 & 3.7807 \\
\hline & & 16 & 3.6578 & 3.6578 & 1.9253 & 1.9221 & 3.6578 & 3.6578 & 3.6689 & 1.9242 & 1.9191 & 3.6578 & 3.6578 & 3.6573 & 1.9238 & 1.9182 & 1.9241 & 1.9189 \\
\hline \multirow{4}{*}{ 2nd year } & \multirow{2}{*}{ SAR } & 4 & 7.8090 & 7.8090 & 7.9482 & 7.7505 & 7.8072 & 7.8036 & 7.8799 & 7.9446 & 7.6914 & 7.8083 & 7.8048 & 7.8602 & 7.9449 & 7.6966 & 7.8694 & 7.7965 \\
\hline & & 16 & 5.1067 & 5.1067 & 4.0015 & 3.9818 & 5.1072 & 5.1071 & 5.1124 & 3.9998 & 3.9529 & 5.1072 & 5.1071 & 5.1245 & 3.9998 & 3.9641 & 4.0009 & 3.9824 \\
\hline & \multirow{2}{*}{ SMA } & 4 & 4.4542 & 4.4542 & 4.2866 & 4.2246 & 4.4542 & 4.4542 & 4.4428 & 4.2851 & 4.2039 & 4.4550 & 4.4550 & 4.4326 & 4.2849 & 4.2010 & 4.2212 & 4.2173 \\
\hline & & 16 & 3.9015 & 3.9015 & 2.1390 & 2.1358 & 3.9020 & 3.9020 & 3.9049 & 2.1379 & 2.1329 & 3.9019 & 3.9020 & 3.9004 & 2.1376 & 2.1321 & 2.1268 & 2.1282 \\
\hline \multirow{4}{*}{ 3rd year } & \multirow{2}{*}{ SAR } & 4 & 8.1109 & 8.1110 & 8.2604 & 8.0514 & 8.1097 & 8.1061 & 8.1691 & 8.2567 & 7.9908 & 8.1108 & 8.1074 & 8.1531 & 8.2570 & 7.9965 & 8.1481 & 8.1222 \\
\hline & & 16 & 5.2802 & 5.2802 & 4.1566 & 4.1380 & 5.2810 & 5.2808 & 5.2830 & 4.1548 & 4.1092 & 5.2811 & 5.2809 & 5.2993 & 4.1548 & 4.1202 & 4.1436 & 4.1359 \\
\hline & \multirow{2}{*}{ SMA } & 4 & 4.6117 & 4.6118 & 4.4413 & 4.3773 & 4.6119 & 4.6119 & 4.6106 & 4.4396 & 4.3562 & 4.6127 & 4.6127 & 4.5981 & 4.4394 & 4.3533 & 4.3891 & 4.3767 \\
\hline & & 16 & 3.9868 & 3.9869 & 2.2197 & 2.2165 & 3.9872 & 3.9873 & 3.9899 & 2.2187 & 2.2138 & 3.9872 & 3.9873 & 3.9852 & 2.2185 & 2.2129 & 2.2159 & 2.2105 \\
\hline & SAB & 4 & 8.2880 & 8.2881 & 8.4361 & 8.2247 & 8.2863 & 8.2825 & 8.3401 & 8.4323 & 8.1646 & 8.2872 & 8.2836 & 8.3265 & 8.4325 & 8.1699 & 8.3174 & 8.2757 \\
\hline & $S A \cap$ & 16 & 5.3754 & 5.3754 & 4.2379 & 4.2203 & 5.3764 & 5.3762 & 5.3696 & 4.2361 & 4.1923 & 5.3764 & 5.3763 & 5.3841 & 4.2362 & 4.2025 & 4.2274 & 4.2159 \\
\hline & SMA & 4 & 4.7001 & 4.7001 & 4.5263 & 4.4619 & 4.7002 & 4.7002 & 4.6970 & 4.5246 & 4.4406 & 4.7011 & 4.7012 & 4.6862 & 4.5243 & 4.4375 & 4.4753 & 4.4638 \\
\hline & & 16 & 4.0305 & 4.0306 & 2.2643 & 2.2611 & 4.0310 & 4.0311 & 4.0350 & 2.2634 & 2.2584 & 4.0310 & 4.0310 & 4.0261 & 2.2632 & 2.2576 & 2.2595 & 2.2564 \\
\hline & SAR & 4 & 8.4030 & 8.4031 & 8.5526 & 8.3403 & 8.4015 & 8.3972 & 8.4337 & 8.5489 & 8.2779 & 8.4025 & 8.3984 & 8.4197 & 8.5491 & 8.2847 & 8.4158 & 8.3736 \\
\hline & & 16 & 5.4232 & 5.4232 & 4.2810 & 4.2636 & 5.4244 & 5.4242 & 5.4204 & 4.2791 & 4.2362 & 5.4243 & 5.4242 & 5.4327 & 4.2792 & 4.2459 & 4.2825 & 4.2742 \\
\hline & SMA & 4 & 4.7576 & 4.7576 & 4.5825 & 4.5177 & 4.7578 & 4.7578 & 4.7505 & 4.5806 & 4.4958 & 4.7588 & 4.7588 & 4.7481 & 4.5804 & 4.4929 & 4.5331 & 4.5198 \\
\hline & SIVIA & 16 & 4.0625 & 4.0625 & 2.2950 & 2.2919 & 4.0630 & 4.0630 & 4.0607 & 2.2940 & 2.2894 & 4.0629 & 4.0630 & 4.0515 & 2.2938 & 2.2886 & 2.2879 & 2.2826 \\
\hline & & 4 & 7.9219 & 7.9219 & 8.0640 & 7.8620 & 7.9204 & 7.9166 & 7.9868 & 8.0603 & 7.8029 & 7.9215 & 7.9178 & 7.9705 & 8.0606 & 7.8083 & 7.9650 & 7.9203 \\
\hline & $S A R$ & 16 & 5.1672 & 5.1672 & 4.0533 & 4.0348 & 5.1679 & 5.1678 & 5.1724 & 4.0514 & 4.0064 & 5.1679 & 5.1678 & 5.1815 & 4.0515 & 4.0171 & 4.0489 & 4.0371 \\
\hline iverage & & 4 & 4.5068 & 4.5068 & 4.3392 & 4.2764 & 4.5068 & 4.5068 & 4.5014 & 4.3376 & 4.2553 & 4.5077 & 4.5077 & 4.4900 & 4.3374 & 4.2525 & 4.2822 & 4.2717 \\
\hline & SIVIA & 16 & 3.9278 & 3.9278 & 2.1687 & 2.1655 & 3.9282 & 3.9282 & 3.9319 & 2.1677 & 2.1627 & 3.9282 & 3.9282 & 3.9241 & 2.1674 & 2.1619 & 2.1629 & 2.1593 \\
\hline
\end{tabular}


Table 8 - Forecasts RMSE - $(\mathrm{N}, \mathrm{T})=(\mathbf{1 0 0}, \mathbf{1 0}), \mathrm{W}(\mathbf{5 , 5}), 1000$ replications $\rho=\lambda=0.8$ for SAR and SMA data generating processes

\begin{tabular}{|c|c|c|c|c|c|c|c|c|c|c|c|c|c|c|c|c|c|c|}
\hline & \multicolumn{18}{|c|}{ Estimators } \\
\hline & \multirow{2}{*}{$\begin{array}{l}\text { true } \\
\text { DGP }\end{array}$} & \multirow[b]{2}{*}{$\sigma_{\mu}^{2}$} & \multirow{2}{*}{$\begin{array}{c}\text { Pooled } \\
\text { OLS }\end{array}$} & \multirow{2}{*}{$\begin{array}{c}\text { Av. hetero. } \\
\text { OLS }\end{array}$} & \multirow{2}{*}{ FE } & \multirow{2}{*}{ RE } & \multirow{2}{*}{$\begin{array}{c}\text { Pooled SAR } \\
\text { MLE }\end{array}$} & \multicolumn{2}{|c|}{ Av. hetero. SAR } & \multirow{2}{*}{$\begin{array}{c}\text { FE-SAR } \\
\text { MLE }\end{array}$} & \multirow{2}{*}{$\begin{array}{c}\text { RE-SAR } \\
\text { MLE }\end{array}$} & \multirow{2}{*}{$\begin{array}{c}\text { Pooled SMA } \\
\text { MLE }\end{array}$} & \multicolumn{2}{|c|}{ Av. hetero. SMA } & \multirow{2}{*}{$\begin{array}{c}\text { FE-SMA } \\
\text { MLE }\end{array}$} & \multirow{2}{*}{$\begin{array}{c}\text { RE-SMA } \\
\text { MLE }\end{array}$} & \multirow{2}{*}{$\begin{array}{c}\text { SAR-RE } \\
\text { GM }\end{array}$} & \multirow{2}{*}{$\begin{array}{c}\text { SMA-RE } \\
\text { GM }\end{array}$} \\
\hline & & & & & & & & MLE & GM & & & & MLE & GM & & & & \\
\hline \multirow{4}{*}{1 st year } & \multirow{2}{*}{ SAR } & 4 & 4.8896 & 4.8896 & 4.8105 & 4.7424 & 4.8891 & 4.8842 & 4.8756 & 4.8090 & 4.7109 & 4.8891 & 4.8843 & 4.8631 & 4.8090 & 4.7104 & 4.7175 & 4.7375 \\
\hline & & 16 & 3.9142 & 3.9142 & 2.3915 & 2.3876 & 3.9141 & 3.9141 & 3.9341 & 2.3908 & 2.3731 & 3.9142 & 3.9142 & 3.9071 & 2.3907 & 2.3804 & 2.3936 & 2.3766 \\
\hline & \multirow{2}{*}{ SMA } & 4 & 3.6481 & 3.6481 & 3.4526 & 3.4061 & 3.6482 & 3.6481 & 3.6569 & 3.4522 & 3.3998 & 3.6482 & 3.6481 & 3.6532 & 3.4521 & 3.3997 & 3.3988 & 3.4030 \\
\hline & & 16 & 3.5641 & 3.5641 & 1.7221 & 1.7201 & 3.5641 & 3.5641 & 3.5640 & 1.7219 & 1.7193 & 3.5641 & 3.5641 & 3.5677 & 1.7219 & 1.7192 & 1.7239 & 1.7176 \\
\hline \multirow{4}{*}{ 2nd year } & \multirow{2}{*}{ SAR } & 4 & 5.4287 & 5.4286 & 5.3436 & 5.2695 & 5.4277 & 5.4231 & 5.4291 & 5.3420 & 5.2336 & 5.4277 & 5.4233 & 5.4096 & 5.3420 & 5.2341 & 5.2488 & 5.2694 \\
\hline & & 16 & 4.2142 & 4.2142 & 2.6762 & 2.6712 & 4.2141 & 4.2141 & 4.2449 & 2.6756 & 2.6548 & 4.2142 & 4.2141 & 4.2210 & 2.6755 & 2.6633 & 2.6632 & 2.6446 \\
\hline & \multirow{2}{*}{ SMA } & 4 & 4.0344 & 4.0344 & 3.8254 & 3.7736 & 4.0346 & 4.0345 & 4.0495 & 3.8250 & 3.7673 & 4.0347 & 4.0346 & 4.0555 & 3.8250 & 3.7669 & 3.7881 & 3.7818 \\
\hline & & 16 & 3.7822 & 3.7822 & 1.9174 & 1.9155 & 3.7823 & 3.7823 & 3.7733 & 1.9172 & 1.9148 & 3.7824 & 3.7824 & 3.7828 & 1.9172 & 1.9147 & 1.9158 & 1.9132 \\
\hline \multirow{4}{*}{ 3rd year } & \multirow{2}{*}{ SAR } & 4 & 5.6536 & 5.6534 & 5.5673 & 5.4915 & 5.6526 & 5.6479 & 5.6420 & 5.5659 & 5.4550 & 5.6526 & 5.6481 & 5.6318 & 5.5659 & 5.4552 & 5.4511 & 5.4916 \\
\hline & & 16 & 4.3316 & 4.3317 & 2.7876 & 2.7825 & 4.3317 & 4.3317 & 4.3494 & 2.7866 & 2.7673 & 4.3318 & 4.3318 & 4.3274 & 2.7866 & 2.7750 & 2.7642 & 2.7511 \\
\hline & \multirow{2}{*}{ SMA } & 4 & 4.1902 & 4.1902 & 3.9751 & 3.9225 & 4.1902 & 4.1902 & 4.2048 & 3.9747 & 3.9163 & 4.1903 & 4.1903 & 4.2137 & 3.9747 & 3.9160 & 3.9417 & 3.9364 \\
\hline & & 16 & 3.8599 & 3.8599 & 1.9944 & 1.9925 & 3.8600 & 3.8600 & 3.8512 & 1.9942 & 1.9919 & 3.8600 & 3.8600 & 3.8547 & 1.9942 & 1.9918 & 1.9915 & 1.9880 \\
\hline & SAR & 4 & 5.7652 & 5.7651 & 5.6767 & 5.6001 & 5.7643 & 5.7593 & 5.7521 & 5.6755 & 5.5624 & 5.7643 & 5.7593 & 5.7516 & 5.6754 & 5.5632 & 5.5707 & 5.6067 \\
\hline 4 th ve & $S A R$ & 16 & 4.3864 & 4.3865 & 2.8394 & 2.8342 & 4.3863 & 4.3863 & 4.4067 & 2.8383 & 2.8181 & 4.3864 & 4.3864 & 4.3796 & 2.8383 & 2.8263 & 2.8198 & 2.8078 \\
\hline 4tn year & $A \mathrm{~A}$ & 4 & 4.2767 & 4.2767 & 4.0579 & 4.0051 & 4.2768 & 4.2768 & 4.2908 & 4.0575 & 3.9988 & 4.2769 & 4.2769 & 4.3000 & 4.0575 & 3.9984 & 4.0228 & 4.0188 \\
\hline & & 16 & 3.8979 & 3.8979 & 2.0318 & 2.0300 & 3.8981 & 3.8981 & 3.8881 & 2.0316 & 2.0294 & 3.8981 & 3.8981 & 3.8923 & 2.0316 & 2.0293 & 2.0310 & 2.0292 \\
\hline & SAR & 4 & 5.8347 & 5.8346 & 5.7504 & 5.6716 & 5.8339 & 5.8290 & 5.8163 & 5.7492 & 5.6306 & 5.8338 & 5.8291 & 5.8164 & 5.7491 & 5.6329 & 5.6386 & 5.6769 \\
\hline & & 16 & 4.4237 & 4.4238 & 2.8759 & 2.8707 & 4.4238 & 4.4238 & 4.4366 & 2.8747 & 2.8544 & 4.4238 & 4.4238 & 4.4162 & 2.8748 & 2.8628 & 2.8540 & 2.8424 \\
\hline & SMA & 4 & 4.3286 & 4.3287 & 4.1070 & 4.0542 & 4.3287 & 4.3287 & 4.3442 & 4.1066 & 4.0478 & 4.3288 & 4.3288 & 4.3505 & 4.1066 & 4.0474 & 4.0702 & 4.0662 \\
\hline & & 16 & 3.9212 & 3.9212 & 2.0574 & 2.0554 & 3.9213 & 3.9214 & 3.9125 & 2.0572 & 2.0547 & 3.9214 & 3.9214 & 3.9139 & 2.0572 & 2.0546 & 2.0560 & 2.0555 \\
\hline & SAR & 4 & 5.5144 & 5.5142 & 5.4297 & 5.3550 & 5.5135 & 5.5087 & 5.5030 & 5.4283 & 5.3185 & 5.5135 & 5.5088 & 5.4945 & 5.4283 & 5.3192 & 5.3254 & 5.3564 \\
\hline & 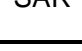 & 16 & 4.2540 & 4.2541 & 2.7141 & 2.7093 & 4.2540 & 4.2540 & 4.2743 & 2.7132 & 2.6935 & 4.2541 & 4.2541 & 4.2502 & 2.7132 & 2.7016 & 2.6990 & 2.6845 \\
\hline & & 4 & 4.0956 & 4.0956 & 3.8836 & 3.8323 & 4.0957 & 4.0957 & 4.1093 & 3.8832 & 3.8260 & 4.0958 & 4.0957 & 4.1146 & 3.8832 & 3.8257 & 3.8443 & 3.8412 \\
\hline & SIVIA & 16 & 3.8051 & 3.8051 & 1.9446 & 1.9427 & 3.8052 & 3.8052 & 3.7978 & 1.9444 & 1.9420 & 3.8052 & 3.8052 & 3.8023 & 1.9444 & 1.9419 & 1.9436 & 1.9407 \\
\hline
\end{tabular}


Table 9 - Forecasts RMSE - $(\mathrm{N}, \mathrm{T})=(\mathbf{5 0 , 1 0 )}$, SAR data generating process for $\phi, \mathrm{W}(\mathbf{1}, \mathbf{1})$ asymmetric weight matrix of French administrative communes, 1000 replications

\begin{tabular}{|c|c|c|c|c|c|c|c|c|c|c|c|c|c|c|c|c|c|c|}
\hline & \multicolumn{18}{|c|}{ Estimators } \\
\hline & \multirow[b]{2}{*}{$\rho$} & \multirow[b]{2}{*}{$\sigma_{\mu}^{2}$} & \multirow{2}{*}{$\begin{array}{l}\text { Pooled } \\
\text { OLS }\end{array}$} & \multirow{2}{*}{$\begin{array}{c}\text { Av. hetero. } \\
\text { OLS }\end{array}$} & \multirow{2}{*}{ FE } & \multirow{2}{*}{$\mathrm{RE}$} & \multirow{2}{*}{$\begin{array}{c}\text { Pooled SAR } \\
\text { MLE }\end{array}$} & \multicolumn{2}{|c|}{ Av. hetero. SAR } & \multirow{2}{*}{$\begin{array}{c}\text { FE-SAR } \\
\text { MLE }\end{array}$} & \multirow{2}{*}{$\begin{array}{c}\text { RE-SAR } \\
\text { MLE }\end{array}$} & \multirow{2}{*}{$\begin{array}{c}\text { Pooled SMA } \\
\text { MLE }\end{array}$} & \multicolumn{2}{|c|}{ Av. hetero. SMA } & \multirow{2}{*}{$\begin{array}{c}\text { FE-SMA } \\
\text { MLE }\end{array}$} & \multirow{2}{*}{$\begin{array}{c}\text { RE-SMA } \\
\text { MLE }\end{array}$} & \multirow{2}{*}{$\begin{array}{c}\text { SAR-RE } \\
\text { GM }\end{array}$} & \multirow{2}{*}{$\begin{array}{c}\text { SMA-RE } \\
\text { GM }\end{array}$} \\
\hline & & & & & & & & MLE & GM & & & & MLE & GM & & & & \\
\hline \multirow{4}{*}{ 1st year } & 0.4 & 4 & 4.1551 & 4.1552 & 4.0358 & 3.9706 & 4.1563 & 4.1564 & 4.2084 & 4.0338 & 3.9550 & 4.1561 & 4.1562 & 4.1772 & 4.0341 & 3.9588 & 3.9718 & 4.0408 \\
\hline & & 16 & 3.6742 & 3.6743 & 2.0307 & 2.0268 & 3.6747 & 3.6746 & 3.7101 & 2.0297 & 2.0240 & 3.6742 & 3.6745 & 3.6869 & 2.0297 & 2.0251 & 2.0188 & 1.7766 \\
\hline & 0.8 & 4 & 9.9810 & 9.9856 & 9.3815 & 9.9337 & 10.0933 & 10.1004 & 9.5173 & 9.3512 & 9.9918 & 10.0797 & 10.0493 & 11.0071 & 9.3561 & 9.5768 & 14.1056 & 11.9221 \\
\hline & & 16 & 6.0600 & 6.0600 & 5.4403 & 5.3955 & 6.0623 & 6.0588 & 6.0347 & 5.4324 & 5.3177 & 6.0619 & 6.0607 & 5.9938 & 5.4322 & 5.3498 & 5.3437 & 5.9137 \\
\hline \multirow{4}{*}{ 2nd year } & 0.4 & 4 & 4.6207 & 4.6208 & 4.4863 & 4.4181 & 4.6216 & 4.6217 & 4.6514 & 4.4840 & 4.4016 & 4.6212 & 4.6213 & 4.6323 & 4.4842 & 4.4058 & 4.4093 & 4.5255 \\
\hline & & 16 & 3.9151 & 3.9152 & 2.2464 & 2.2423 & 3.9160 & 3.9158 & 3.9599 & 2.2455 & 2.2397 & 3.9155 & 3.9157 & 3.9448 & 2.2456 & 2.2411 & 2.2401 & 2.0398 \\
\hline & 0.8 & 4 & 11.1618 & 11.1681 & 11.4312 & 11.1342 & 11.1617 & 11.1559 & 10.6685 & 11.3428 & 11.4194 & 11.1554 & 11.1523 & 13.2402 & 11.3491 & 11.0807 & 14.8653 & 12.0044 \\
\hline & & 16 & 6.6797 & 6.6797 & 5.9939 & 5.9463 & 6.6853 & 6.6811 & 6.6860 & 5.9864 & 5.8707 & 6.6823 & 6.6810 & 6.6818 & 5.9864 & 5.9005 & 5.9473 & 6.9897 \\
\hline \multirow{4}{*}{ 3rd year } & 0.4 & 4 & 4.8019 & 4.8020 & 4.6608 & 4.5919 & 4.8022 & 4.8024 & 4.8187 & 4.6587 & 4.5759 & 4.8019 & 4.8020 & 4.8093 & 4.6589 & 4.5792 & 4.5873 & 4.6235 \\
\hline & & 16 & 4.0085 & 4.0086 & 2.3379 & 2.3335 & 4.0098 & 4.0096 & 4.0529 & 2.3368 & 2.3305 & 4.0094 & 4.0095 & 4.0385 & 2.3368 & 2.3322 & 2.3302 & 2.2916 \\
\hline & 0.8 & 4 & 12.5896 & 12.5954 & 13.0581 & 12.5818 & 12.6034 & 12.6015 & 11.1090 & 13.0022 & 12.8293 & 12.5959 & 12.5869 & 13.5612 & 13.0067 & 12.6192 & 14.0236 & 11.8049 \\
\hline & & 16 & 6.9318 & 6.9319 & 6.2300 & 6.1842 & 6.9396 & 6.9351 & 6.9420 & 6.2227 & 6.1073 & 6.9354 & 6.9344 & 6.9338 & 6.2228 & 6.1366 & 6.2060 & 6.5267 \\
\hline \multirow{4}{*}{ 4th year } & 0.4 & 4 & 4.9024 & 4.9025 & 4.7604 & 4.6903 & 4.9028 & 4.9029 & 4.9106 & 4.7582 & 4.6746 & 4.9027 & 4.9029 & 4.9074 & 4.7585 & 4.6782 & 4.6926 & 4.8674 \\
\hline & & 16 & 4.0589 & 4.0591 & 2.3835 & 2.3794 & 4.0601 & 4.0599 & 4.0965 & 2.3825 & 2.3767 & 4.0597 & 4.0598 & 4.0885 & 2.3825 & 2.3782 & 2.3710 & 2.4283 \\
\hline & 0.8 & 4 & 13.0269 & 13.0318 & 13.3271 & 13.0157 & 13.0225 & 13.0203 & 12.1625 & 13.3052 & 13.1667 & 13.0220 & 13.0217 & 13.7779 & 13.3076 & 12.9671 & 14.0499 & 12.3835 \\
\hline & & 16 & 7.0667 & 7.0667 & 6.3577 & 6.3117 & 7.0745 & 7.0700 & 7.0763 & 6.3503 & 6.2328 & 7.0698 & 7.0689 & 7.0685 & 6.3505 & 6.2637 & 6.3310 & 6.3103 \\
\hline \multirow{4}{*}{ 5th year } & 0.4 & 4 & 4.9614 & 4.9616 & 4.8170 & 4.7469 & 4.9618 & 4.9620 & 4.9720 & 4.8148 & 4.7308 & 4.9617 & 4.9619 & 4.9667 & 4.8151 & 4.7346 & 4.7497 & 4.8157 \\
\hline & & 16 & 4.0865 & 4.0866 & 2.4125 & 2.4084 & 4.0876 & 4.0875 & 4.1232 & 2.4114 & 2.4058 & 4.0872 & 4.0874 & 4.1151 & 2.4114 & 2.4071 & 2.4017 & 2.5225 \\
\hline & 0.8 & 4 & 13.4890 & 13.4947 & 13.7509 & 13.4767 & 13.4764 & 13.4771 & 13.2666 & 13.7220 & 13.5829 & 13.4730 & 13.4675 & 14.1849 & 13.7242 & 13.4160 & 13.9525 & 12.2767 \\
\hline & & 16 & 7.1538 & 7.1538 & 6.4418 & 6.3950 & 7.1625 & 7.1581 & 7.1581 & 6.4340 & 6.3148 & 7.1575 & 7.1566 & 7.1510 & 6.4342 & 6.3459 & 6.4185 & 6.3724 \\
\hline \multirow{4}{*}{ Average } & 0.4 & 4 & 4.6883 & 4.6884 & 4.5521 & 4.4836 & 4.6889 & 4.6891 & 4.7122 & 4.5499 & 4.4676 & 4.6887 & 4.6889 & 4.6986 & 4.5502 & 4.4713 & 4.4821 & 4.5746 \\
\hline & & 16 & 3.9486 & 3.9488 & 2.2822 & 2.2781 & 3.9496 & 3.9495 & 3.9885 & 2.2812 & 2.2753 & 3.9492 & 3.9494 & 3.9748 & 2.2812 & 2.2768 & 2.2724 & 2.2118 \\
\hline & 0.8 & 4 & 12.0497 & 12.0551 & 12.1897 & 12.0284 & 12.0715 & 12.0710 & 11.3448 & 12.1447 & 12.1980 & 12.0652 & 12.0556 & 13.1542 & 12.1487 & 11.9319 & 14.1994 & 12.0783 \\
\hline & & 16 & 6.7784 & 6.7784 & 6.0928 & 6.0465 & 6.7848 & 6.7806 & 6.7794 & 6.0851 & 5.9687 & 6.7814 & 6.7803 & 6.7658 & 6.0852 & 5.9993 & 6.0493 & 6.4226 \\
\hline
\end{tabular}


Table 10 - Forecasts RMSE - $(\mathrm{N}, \mathrm{T})=(50,10)$, SMA data generating process for $\phi, \mathrm{W}(\mathbf{1 , 1})$ asymmetric weight matrix of French administrative communes, 1000 replications

\begin{tabular}{|c|c|c|c|c|c|c|c|c|c|c|c|c|c|c|c|c|c|c|}
\hline & \multicolumn{18}{|c|}{ Estimators } \\
\hline & \multirow[b]{2}{*}{$\lambda$} & \multirow[b]{2}{*}{$\sigma_{\mu}^{2}$} & \multirow{2}{*}{$\begin{array}{c}\text { Pooled } \\
\text { OLS }\end{array}$} & \multirow{2}{*}{$\begin{array}{c}\text { Av. hetero. } \\
\text { OLS }\end{array}$} & \multirow{2}{*}{ FE } & \multirow{2}{*}{ RE } & \multirow{2}{*}{$\begin{array}{c}\text { Pooled SAR } \\
\text { MLE }\end{array}$} & \multicolumn{2}{|c|}{ Av. hetero. SAR } & \multirow{2}{*}{$\begin{array}{c}\text { FE-SAR } \\
\text { MLE }\end{array}$} & \multirow{2}{*}{$\begin{array}{c}\text { RE-SAR } \\
\text { MLE }\end{array}$} & \multirow{2}{*}{$\begin{array}{c}\text { Pooled SMA } \\
\text { MLE }\end{array}$} & \multicolumn{2}{|c|}{ Av. hetero. SMA } & \multirow{2}{*}{$\begin{array}{c}\text { FE-SMA } \\
\text { MLE }\end{array}$} & \multirow{2}{*}{$\begin{array}{c}\text { RE-SMA } \\
\text { MLE }\end{array}$} & \multirow{2}{*}{$\begin{array}{c}\text { SAR-RE } \\
\text { GM }\end{array}$} & \multirow{2}{*}{$\begin{array}{c}\text { SMA-RE } \\
\text { GM }\end{array}$} \\
\hline & & & & & & & & MLE & GM & & & & MLE & GM & & & & \\
\hline \multirow{4}{*}{1 st year } & 0.4 & 4 & 3.7809 & 3.7808 & 3.5814 & 3.5379 & 3.7822 & 3.7821 & 3.8043 & 3.5791 & 3.5262 & 3.7831 & 3.7829 & 3.7746 & 3.5791 & 3.5277 & 3.5663 & 3.5515 \\
\hline & & 16 & 3.5887 & 3.5886 & 1.8019 & 1.8003 & 3.5895 & 3.5894 & 3.6027 & 1.8010 & 1.7993 & 3.5901 & 3.5897 & 3.5790 & 1.8010 & 1.7993 & 1.8095 & 1.8088 \\
\hline & 0.8 & 4 & 4.3674 & 4.3676 & 4.2789 & 4.1978 & 4.3665 & 4.3666 & 4.3992 & 4.2743 & 4.1715 & 4.3663 & 4.3664 & 4.3773 & 4.2727 & 4.1660 & 4.2319 & 4.2213 \\
\hline & & 16 & 3.7471 & 3.7470 & 2.1479 & 2.1440 & 3.7489 & 3.7487 & 3.7494 & 2.1466 & 2.1407 & 3.7492 & 3.7484 & 3.7325 & 2.1463 & 2.1395 & 2.1355 & 2.1329 \\
\hline \multirow{4}{*}{ 2nd year } & 0.4 & 4 & 4.1973 & 4.1973 & 3.9972 & 3.9465 & 4.1982 & 4.1985 & 4.2122 & 3.9952 & 3.9346 & 4.1988 & 4.1989 & 4.1837 & 3.9952 & 3.9355 & 3.9610 & 3.9549 \\
\hline & & 16 & 3.8053 & 3.8053 & 1.9898 & 1.9884 & 3.8064 & 3.8065 & 3.8219 & 1.9892 & 1.9874 & 3.8072 & 3.8066 & 3.8084 & 1.9892 & 1.9874 & 2.0021 & 2.0062 \\
\hline & 0.8 & 4 & 4.8689 & 4.8690 & 4.7680 & 4.6864 & 4.8694 & 4.8693 & 4.8883 & 4.7639 & 4.6591 & 4.8690 & 4.8690 & 4.8525 & 4.7622 & 4.6534 & 4.7003 & 4.6877 \\
\hline & & 16 & 4.0193 & 4.0193 & 2.3854 & 2.3817 & 4.0204 & 4.0204 & 4.0244 & 2.3835 & 2.3781 & 4.0206 & 4.0201 & 4.0001 & 2.3832 & 2.3770 & 2.3821 & 2.3708 \\
\hline \multirow{4}{*}{ 3rd year } & 0.4 & 4 & 4.3641 & 4.3642 & 4.1645 & 4.1114 & 4.3649 & 4.3653 & 4.3629 & 4.1625 & 4.0999 & 4.3657 & 4.3657 & 4.3599 & 4.1624 & 4.1003 & 4.1042 & 4.1069 \\
\hline & & 16 & 3.8871 & 3.8872 & 2.0752 & 2.0738 & 3.8877 & 3.8879 & 3.8996 & 2.0745 & 2.0727 & 3.8884 & 3.8880 & 3.8903 & 2.0744 & 2.0725 & 2.0785 & 2.0819 \\
\hline & 0.8 & 4 & 5.0644 & 5.0644 & 4.9605 & 4.8799 & 5.0650 & 5.0649 & 5.0699 & 4.9569 & 4.8509 & 5.0647 & 5.0647 & 5.0435 & 4.9556 & 4.8451 & 4.8845 & 4.8738 \\
\hline & & 16 & 4.1141 & 4.1141 & 2.4801 & 2.4761 & 4.1157 & 4.1156 & 4.1222 & 2.4781 & 2.4720 & 4.1159 & 4.1155 & 4.0955 & 2.4777 & 2.4708 & 2.4713 & 2.4660 \\
\hline \multirow{4}{*}{ 4th year } & 0.4 & 4 & 4.4458 & 4.4459 & 4.2439 & 4.1899 & 4.4471 & 4.4474 & 4.4539 & 4.2419 & 4.1787 & 4.4478 & 4.4477 & 4.4435 & 4.2418 & 4.1791 & 4.1901 & 4.1942 \\
\hline & & 16 & 3.9249 & 3.9250 & 2.1216 & 2.1196 & 3.9255 & 3.9258 & 3.9445 & 2.1209 & 2.1183 & 3.9262 & 3.9259 & 3.9344 & 2.1208 & 2.1182 & 2.1195 & 2.1222 \\
\hline & 0.8 & 4 & 5.1625 & 5.1626 & 5.0576 & 4.9749 & 5.1629 & 5.1628 & 5.1742 & 5.0533 & 4.9453 & 5.1631 & 5.1631 & 5.1466 & 5.0519 & 4.9399 & 4.9794 & 4.9755 \\
\hline & & 16 & 4.1643 & 4.1644 & 2.5301 & 2.5259 & 4.1661 & 4.1661 & 4.1721 & 2.5278 & 2.5212 & 4.1664 & 4.1660 & 4.1469 & 2.5272 & 2.5200 & 2.5214 & 2.5224 \\
\hline \multirow{4}{*}{5 th year } & 0.4 & 4 & 4.4976 & 4.4977 & 4.2964 & 4.2411 & 4.4986 & 4.4989 & 4.5052 & 4.2943 & 4.2302 & 4.4992 & 4.4992 & 4.5008 & 4.2943 & 4.2305 & 4.2456 & 4.2445 \\
\hline & & 16 & 3.9472 & 3.9473 & 2.1446 & 2.1425 & 3.9478 & 3.9480 & 3.9653 & 2.1438 & 2.1411 & 3.9484 & 3.9481 & 3.9564 & 2.1438 & 2.1411 & 2.1458 & 2.1490 \\
\hline & 0.8 & 4 & 5.2171 & 5.2172 & 5.1101 & 5.0272 & 5.2179 & 5.2177 & 5.2409 & 5.1059 & 4.9979 & 5.2184 & 5.2184 & 5.2129 & 5.1047 & 4.9916 & 5.0386 & 5.0420 \\
\hline & & 16 & 4.1913 & 4.1913 & 2.5593 & 2.5551 & 4.1929 & 4.1929 & 4.2007 & 2.5570 & 2.5505 & 4.1932 & 4.1928 & 4.1792 & 2.5565 & 2.5493 & 2.5579 & 2.5532 \\
\hline \multirow{4}{*}{ Average } & 0.4 & 4 & 4.2571 & 4.2572 & 4.0567 & 4.0053 & 4.2582 & 4.2584 & 4.2677 & 4.0546 & 3.9939 & 4.2589 & 4.2589 & 4.2525 & 4.0546 & 3.9946 & 4.0135 & 4.0104 \\
\hline & & 16 & 3.8307 & 3.8307 & 2.0266 & 2.0249 & 3.8314 & 3.8315 & 3.8468 & 2.0259 & 2.0238 & 3.8321 & 3.8317 & 3.8337 & 2.0258 & 2.0237 & 2.0311 & 2.0336 \\
\hline & 0.8 & 4 & 4.9361 & 4.9362 & 4.8350 & 4.7532 & 4.9363 & 4.9362 & 4.9545 & 4.8309 & 4.7249 & 4.9363 & 4.9363 & 4.9266 & 4.8294 & 4.7192 & 4.7669 & 4.7601 \\
\hline & & 16 & 4.0472 & 4.0472 & 2.4206 & 2.4166 & 4.0488 & 4.0488 & 4.0538 & 2.4186 & 2.4125 & 4.0491 & 4.0486 & 4.0308 & 2.4182 & 2.4113 & 2.4137 & 2.4090 \\
\hline
\end{tabular}


Table 11 - Forecasts RMSE - $(\mathrm{N}, \mathrm{T})=(50,10)$, SAR data generating process for $\phi, W(5,5)$ asymmetric weight matrix of French administrative communes, 1000 replications

\begin{tabular}{|c|c|c|c|c|c|c|c|c|c|c|c|c|c|c|c|c|c|c|}
\hline & \multirow[b]{3}{*}{$\rho$} & \multirow[b]{3}{*}{$\sigma_{\mu}^{2}$} & \multicolumn{16}{|c|}{ Estimators } \\
\hline & & & \multirow{2}{*}{$\begin{array}{c}\text { Pooled } \\
\text { OLS }\end{array}$} & \multirow{2}{*}{$\begin{array}{c}\text { Av. hetero. } \\
\text { OLS }\end{array}$} & \multirow{2}{*}{ FE } & \multirow{2}{*}{ RE } & \multirow{2}{*}{$\begin{array}{c}\text { Pooled SAR } \\
\text { MLE }\end{array}$} & \multicolumn{2}{|c|}{ Av. hetero. SAR } & \multirow{2}{*}{$\begin{array}{c}\text { FE-SAR } \\
\text { MLE }\end{array}$} & \multirow{2}{*}{$\begin{array}{c}\text { RE-SAR } \\
\text { MLE }\end{array}$} & \multirow{2}{*}{$\begin{array}{c}\text { Pooled SMA } \\
\text { MLE }\end{array}$} & \multicolumn{2}{|c|}{ Av. hetero. SMA } & \multirow{2}{*}{$\begin{array}{c}\text { FE-SMA } \\
\text { MLE }\end{array}$} & \multirow{2}{*}{$\begin{array}{c}\text { RE-SMA } \\
\text { MLE }\end{array}$} & \multirow{2}{*}{$\begin{array}{c}\text { SAR-RE } \\
\text { GM }\end{array}$} & \multirow{2}{*}{$\begin{array}{c}\text { SMA-RE } \\
\text { GM }\end{array}$} \\
\hline & & & & & & & & MLE & GM & & & & MLE & GM & & & & \\
\hline \multirow{4}{*}{ 1st year } & 0.4 & 4 & 3.7378 & 3.7381 & 3.5505 & 3.5077 & 3.7375 & 3.7376 & 3.7345 & 3.5494 & 3.5024 & 3.7375 & 3.7377 & 3.7351 & 3.5494 & 3.5008 & 3.5002 & 3.7998 \\
\hline & & 16 & 3.5580 & 3.5581 & 1.7728 & 1.7699 & 3.5603 & 3.5595 & 3.5726 & 1.7726 & 1.7690 & 3.5589 & 3.5593 & 3.5620 & 1.7726 & 1.7692 & 1.7776 & 1.9072 \\
\hline & 0.8 & 4 & 5.7212 & 5.7210 & 5.6986 & 5.6317 & 5.7122 & 5.6908 & 5.7728 & 5.6943 & 5.6694 & 5.7170 & 5.7194 & 5.6710 & 5.6944 & 5.5835 & 5.7257 & 6.5819 \\
\hline & & 16 & 4.1824 & 4.1824 & 2.8355 & 2.8319 & 4.1857 & 4.1826 & 4.1996 & 2.8337 & 2.8071 & 4.1829 & 4.1819 & 4.2006 & 2.8338 & 2.8200 & 2.8318 & 3.3513 \\
\hline \multirow{4}{*}{ 2nd year } & 0.4 & 4 & 4.1233 & 4.1237 & 3.9270 & 3.8750 & 4.1234 & 4.1239 & 4.1296 & 3.9263 & 3.8712 & 4.1232 & 4.1236 & 4.1446 & 3.9264 & 3.8691 & 3.8801 & 3.9050 \\
\hline & & 16 & 3.7876 & 3.7877 & 1.9771 & 1.9748 & 3.7894 & 3.7887 & 3.7993 & 1.9769 & 1.9741 & 3.7883 & 3.7887 & 3.7848 & 1.9769 & 1.9745 & 1.9719 & 2.0943 \\
\hline & 0.8 & 4 & 6.3676 & 6.3677 & 6.3403 & 6.2672 & 6.3531 & 6.3335 & 6.3887 & 6.3362 & 6.3238 & 6.3609 & 6.3589 & 6.3212 & 6.3364 & 6.2137 & 6.3270 & 5.7960 \\
\hline & & 16 & 4.5451 & 4.5452 & 3.1584 & 3.1544 & 4.5496 & 4.5451 & 4.5415 & 3.1565 & 3.1296 & 4.5461 & 4.5448 & 4.5448 & 3.1566 & 3.1418 & 3.1552 & 3.6714 \\
\hline \multirow{4}{*}{ 3rd year } & 0.4 & 4 & 4.2904 & 4.2906 & 4.0876 & 4.0360 & 4.2905 & 4.2908 & 4.2843 & 4.0868 & 4.0321 & 4.2904 & 4.2905 & 4.3064 & 4.0869 & 4.0301 & 4.0363 & 4.1751 \\
\hline & & 16 & 3.8611 & 3.8612 & 2.0518 & 2.0494 & 3.8630 & 3.8622 & 3.8770 & 2.0516 & 2.0485 & 3.8618 & 3.8622 & 3.8666 & 2.0516 & 2.0490 & 2.0452 & 2.0835 \\
\hline & 0.8 & 4 & 6.6165 & 6.6168 & 6.5966 & 6.5164 & 6.6021 & 6.5814 & 6.6730 & 6.5927 & 6.5671 & 6.6102 & 6.6083 & 6.5702 & 6.5928 & 6.4634 & 6.5194 & 6.3848 \\
\hline & & 16 & 4.6793 & 4.6792 & 3.2918 & 3.2870 & 4.6832 & 4.6791 & 4.6847 & 3.2897 & 3.2589 & 4.6803 & 4.6788 & 4.6760 & 3.2898 & 3.2735 & 3.2866 & 3.3368 \\
\hline \multirow{4}{*}{4 th year } & 0.4 & 4 & 4.3835 & 4.3838 & 4.1786 & 4.1261 & 4.3837 & 4.3840 & 4.3727 & 4.1777 & 4.1220 & 4.3836 & 4.3838 & 4.3891 & 4.1778 & 4.1205 & 4.1130 & 4.0951 \\
\hline & & 16 & 3.9001 & 3.9002 & 2.0885 & 2.0863 & 3.9021 & 3.9014 & 3.9155 & 2.0883 & 2.0854 & 3.9009 & 3.9014 & 3.9083 & 2.0883 & 2.0859 & 2.0873 & 2.2285 \\
\hline & 0.8 & 4 & 6.7475 & 6.7479 & 6.7260 & 6.6453 & 6.7361 & 6.7144 & 6.7928 & 6.7211 & 6.6999 & 6.7415 & 6.7384 & 6.7232 & 6.7213 & 6.5918 & 6.6467 & 6.6437 \\
\hline & & 16 & 4.7503 & 4.7503 & 3.3568 & 3.3523 & 4.7549 & 4.7504 & 4.7473 & 3.3547 & 3.3262 & 4.7519 & 4.7503 & 4.7426 & 3.3548 & 3.3394 & 3.3510 & 3.2717 \\
\hline \multirow{4}{*}{5 th year } & 0.4 & 4 & 4.4334 & 4.4337 & 4.2277 & 4.1747 & 4.4336 & 4.4338 & 4.4326 & 4.2268 & 4.1704 & 4.4335 & 4.4336 & 4.4434 & 4.2268 & 4.1689 & 4.1664 & 4.2339 \\
\hline & & 16 & 3.9201 & 3.9203 & 2.1117 & 2.1092 & 3.9221 & 3.9214 & 3.9399 & 2.1115 & 2.1084 & 3.9210 & 3.9214 & 3.9338 & 2.1115 & 2.1089 & 2.1097 & 2.2687 \\
\hline & 0.8 & 4 & 6.8084 & 6.8087 & 6.7852 & 6.7061 & 6.7956 & 6.7748 & 6.8683 & 6.7804 & 6.7546 & 6.8021 & 6.7968 & 6.8067 & 6.7807 & 6.6514 & 6.7120 & 6.7112 \\
\hline & & 16 & 4.7890 & 4.7889 & 3.3940 & 3.3894 & 4.7937 & 4.7892 & 4.7822 & 3.3921 & 3.3628 & 4.7907 & 4.7889 & 4.7875 & 3.3922 & 3.3763 & 3.3955 & 3.3104 \\
\hline \multirow{4}{*}{ Average } & 0.4 & 4 & 4.1937 & 4.1940 & 3.9942 & 3.9439 & 4.1937 & 4.1940 & 4.1907 & 3.9934 & 3.9396 & 4.1936 & 4.1938 & 4.2037 & 3.9934 & 3.9379 & 3.9392 & 4.0418 \\
\hline & & 16 & 3.8054 & 3.8055 & 2.0004 & 1.9979 & 3.8074 & 3.8066 & 3.8208 & 2.0002 & 1.9971 & 3.8062 & 3.8066 & 3.8111 & 2.0002 & 1.9975 & 1.9983 & 2.1165 \\
\hline & 0.8 & 4 & 6.4522 & 6.4524 & 6.4293 & 6.3534 & 6.4398 & 6.4190 & 6.4991 & 6.4250 & 6.4030 & 6.4463 & 6.4444 & 6.4185 & 6.4251 & 6.3008 & 6.3862 & 6.4235 \\
\hline & & 16 & 4.5892 & 4.5892 & 3.2073 & 3.2030 & 4.5934 & 4.5893 & 4.5911 & 3.2053 & 3.1769 & 4.5904 & 4.5889 & 4.5903 & 3.2054 & 3.1902 & 3.2040 & 3.3883 \\
\hline
\end{tabular}


Table 12 - Forecasts RMSE - $(\mathrm{N}, \mathrm{T})=(50,10)$, SMA data generating process for $\phi, \mathrm{W}(5,5)$ asymmetric weight matrix of French administrative communes, 1000 replications

\begin{tabular}{|c|c|c|c|c|c|c|c|c|c|c|c|c|c|c|c|c|c|c|}
\hline & \multicolumn{18}{|c|}{ Estimators } \\
\hline & \multirow[b]{2}{*}{$\lambda$} & \multirow[b]{2}{*}{$\sigma_{\mu}^{2}$} & \multirow{2}{*}{$\begin{array}{c}\text { Pooled } \\
\text { OLS }\end{array}$} & \multirow{2}{*}{$\begin{array}{c}\text { Av. hetero. } \\
\text { OLS }\end{array}$} & \multirow{2}{*}{ FE } & \multirow{2}{*}{$\mathrm{RE}$} & \multirow{2}{*}{$\begin{array}{c}\text { Pooled SAR } \\
\text { MLE }\end{array}$} & \multicolumn{2}{|c|}{ Av. hetero. SAR } & \multirow{2}{*}{$\begin{array}{c}\text { FE-SAR } \\
\text { MLE }\end{array}$} & \multirow{2}{*}{$\begin{array}{c}\text { RE-SAR } \\
\text { MLE }\end{array}$} & \multirow{2}{*}{$\begin{array}{c}\text { Pooled SMA } \\
\text { MLE }\end{array}$} & \multicolumn{2}{|c|}{ Av. hetero. SMA } & \multirow{2}{*}{$\begin{array}{c}\text { FE-SMA } \\
\text { MLE }\end{array}$} & \multirow{2}{*}{$\begin{array}{c}\text { RE-SMA } \\
\text { MLE }\end{array}$} & \multirow{2}{*}{$\begin{array}{c}\text { SAR-RE } \\
\text { GM }\end{array}$} & \multirow{2}{*}{$\begin{array}{c}\text { SMA-RE } \\
\text { GM }\end{array}$} \\
\hline & & & & & & & & $\mathrm{ML}$ & GM & & & & $\mathrm{ML}$ & GM & & & & \\
\hline \multirow{4}{*}{1 st year } & 0.4 & 4 & 3.5992 & 3.5992 & 3.4169 & 3.3717 & 3.5997 & 3.5999 & 3.6059 & 3.4164 & 3.3749 & 3.5996 & 3.5996 & 3.6014 & 3.4164 & 3.3691 & 3.3497 & 3.4269 \\
\hline & & 16 & 3.5402 & 3.5402 & 1.6946 & 1.6936 & 3.5413 & 3.5414 & 3.5182 & 1.6944 & 1.6935 & 3.5413 & 3.5415 & 3.5471 & 1.6944 & 1.6943 & 1.7046 & 1.6667 \\
\hline & 0.8 & 4 & 3.7404 & 3.7406 & 3.5619 & 3.5171 & 3.7423 & 3.7402 & 3.7387 & 3.5615 & 3.5079 & 3.7397 & 3.7395 & 3.7386 & 3.5614 & 3.5051 & 3.4983 & 3.7018 \\
\hline & & 16 & 3.5763 & 3.5763 & 1.7736 & 1.7724 & 3.5784 & 3.5768 & 3.5765 & 1.7733 & 1.7717 & 3.5761 & 3.5766 & 3.5518 & 1.7733 & 1.7719 & 1.7671 & 1.9863 \\
\hline \multirow{4}{*}{ 2nd year } & 0.4 & 4 & 3.9882 & 3.9883 & 3.7807 & 3.7315 & 3.9886 & 3.9885 & 3.9929 & 3.7803 & 3.7346 & 3.9885 & 3.9885 & 3.9787 & 3.7804 & 3.7292 & 3.7141 & 3.7752 \\
\hline & & 16 & 3.7325 & 3.7326 & 1.8843 & 1.8820 & 3.7337 & 3.7335 & 3.7255 & 1.8841 & 1.8820 & 3.7333 & 3.7336 & 3.7482 & 1.8841 & 1.8824 & 1.8924 & 1.8990 \\
\hline & 0.8 & 4 & 4.1487 & 4.1488 & 3.9466 & 3.8985 & 4.1508 & 4.1490 & 4.1595 & 3.9463 & 3.8911 & 4.1484 & 4.1482 & 4.1572 & 3.9463 & 3.8876 & 3.9060 & 4.0544 \\
\hline & & 16 & 3.7945 & 3.7945 & 1.9649 & 1.9636 & 3.7965 & 3.7950 & 3.7956 & 1.9645 & 1.9631 & 3.7946 & 3.7949 & 3.7681 & 1.9645 & 1.9632 & 1.9608 & 2.1374 \\
\hline \multirow{4}{*}{ 3rd year } & 0.4 & 4 & 4.1439 & 4.1440 & 3.9258 & 3.8766 & 4.1441 & 4.1442 & 4.1404 & 3.9253 & 3.8806 & 4.1441 & 4.1442 & 4.1386 & 3.9253 & 3.8742 & 3.8689 & 3.9639 \\
\hline & & 16 & 3.8086 & 3.8087 & 1.9598 & 1.9574 & 3.8097 & 3.8094 & 3.8019 & 1.9596 & 1.9574 & 3.8092 & 3.8094 & 3.8260 & 1.9596 & 1.9580 & 1.9655 & 1.9680 \\
\hline & 0.8 & 4 & 4.3099 & 4.3100 & 4.1039 & 4.0546 & 4.3127 & 4.3109 & 4.3117 & 4.1034 & 4.0469 & 4.3097 & 4.3096 & 4.3163 & 4.1034 & 4.0436 & 4.0568 & 4.0984 \\
\hline & & 16 & 3.8692 & 3.8693 & 2.0447 & 2.0431 & 3.8721 & 3.8702 & 3.8734 & 2.0443 & 2.0424 & 3.8699 & 3.8701 & 3.8470 & 2.0442 & 2.0425 & 2.0438 & 2.1830 \\
\hline \multirow{4}{*}{ 4th year } & 0.4 & 4 & 4.2235 & 4.2236 & 3.9988 & 3.9501 & 4.2239 & 4.2240 & 4.2289 & 3.9984 & 3.9547 & 4.2238 & 4.2240 & 4.2267 & 3.9984 & 3.9480 & 3.9478 & 4.0507 \\
\hline & & 16 & 3.8489 & 3.8490 & 2.0028 & 2.0005 & 3.8499 & 3.8498 & 3.8420 & 2.0026 & 2.0006 & 3.8495 & 3.8498 & 3.8650 & 2.0026 & 2.0011 & 2.0032 & 1.9883 \\
\hline & 0.8 & 4 & 4.3863 & 4.3865 & 4.1806 & 4.1298 & 4.3888 & 4.3869 & 4.3979 & 4.1799 & 4.1220 & 4.3861 & 4.3860 & 4.4070 & 4.1799 & 4.1188 & 4.1376 & 4.3898 \\
\hline & & 16 & 3.9086 & 3.9086 & 2.0920 & 2.0902 & 3.9114 & 3.9097 & 3.9116 & 2.0916 & 2.0894 & 3.9094 & 3.9096 & 3.8932 & 2.0916 & 2.0895 & 2.0859 & 2.1698 \\
\hline \multirow{4}{*}{ 5th year } & 0.4 & 4 & 4.2738 & 4.2739 & 4.0483 & 3.9994 & 4.2743 & 4.2744 & 4.2805 & 4.0478 & 4.0040 & 4.2742 & 4.2744 & 4.2790 & 4.0478 & 3.9974 & 3.9973 & 4.0307 \\
\hline & & 16 & 3.8698 & 3.8699 & 2.0246 & 2.0222 & 3.8708 & 3.8706 & 3.8620 & 2.0244 & 2.0223 & 3.8704 & 3.8707 & 3.8878 & 2.0244 & 2.0228 & 2.0260 & 1.9919 \\
\hline & 0.8 & 4 & 4.4411 & 4.4412 & 4.2345 & 4.1830 & 4.4432 & 4.4420 & 4.4491 & 4.2337 & 4.1754 & 4.4410 & 4.4410 & 4.4584 & 4.2337 & 4.1723 & 4.1896 & 4.3298 \\
\hline & & 16 & 3.9337 & 3.9338 & 2.1190 & 2.1171 & 3.9367 & 3.9350 & 3.9372 & 2.1186 & 2.1163 & 3.9347 & 3.9348 & 3.9176 & 2.1185 & 2.1163 & 2.1123 & 2.2562 \\
\hline \multirow{4}{*}{ Average } & 0.4 & 4 & 4.0457 & 4.0458 & 3.8341 & 3.7859 & 4.0461 & 4.0462 & 4.0497 & 3.8337 & 3.7898 & 4.0461 & 4.0461 & 4.0449 & 3.8337 & 3.7836 & 3.7756 & 3.8495 \\
\hline & & 16 & 3.7600 & 3.7601 & 1.9132 & 1.9112 & 3.7611 & 3.7609 & 3.7499 & 1.9130 & 1.9112 & 3.7607 & 3.7610 & 3.7748 & 1.9130 & 1.9117 & 1.9183 & 1.9028 \\
\hline & 0.8 & 4 & 4.2053 & 4.2054 & 4.0055 & 3.9566 & 4.2076 & 4.2058 & 4.2114 & 4.0050 & 3.9486 & 4.2050 & 4.2049 & 4.2155 & 4.0050 & 3.9455 & 3.9577 & 4.1148 \\
\hline & & 16 & 3.8164 & 3.8165 & 1.9989 & 1.9973 & 3.8190 & 3.8174 & 3.8188 & 1.9984 & 1.9966 & 3.8169 & 3.8172 & 3.7955 & 1.9984 & 1.9967 & 1.9940 & 2.1465 \\
\hline
\end{tabular}


Table 13 - Forecasts RMSE - $(\mathrm{N}, \mathrm{T})=(\mathbf{5 0 , 1 0})$, SAR data generating process for $\phi, W(1,1), 1000$ replications under non-normality of individual effects

\begin{tabular}{|c|c|c|c|c|c|c|c|c|c|c|c|c|c|c|c|c|c|c|}
\hline & \multicolumn{18}{|c|}{ Estimators } \\
\hline & \multirow[b]{2}{*}{$\rho$} & \multirow[b]{2}{*}{$\sigma_{\mu}^{2}$} & \multirow{2}{*}{$\begin{array}{l}\text { Pooled } \\
\text { OLS }\end{array}$} & \multirow{2}{*}{$\begin{array}{c}\text { Av. hetero. } \\
\text { OLS }\end{array}$} & \multirow{2}{*}{ FE } & \multirow{2}{*}{ RE } & \multirow{2}{*}{$\begin{array}{c}\text { Pooled SAR } \\
\text { MLE }\end{array}$} & \multicolumn{2}{|c|}{ Av. hetero. SAR } & \multirow{2}{*}{$\begin{array}{c}\text { FE-SAR } \\
\text { MLE }\end{array}$} & \multirow{2}{*}{$\begin{array}{c}\text { RE-SAR } \\
\text { MLE }\end{array}$} & \multirow{2}{*}{$\begin{array}{c}\text { Pooled SMA } \\
\text { MLE }\end{array}$} & \multicolumn{2}{|c|}{ Av. hetero. SMA } & \multirow{2}{*}{$\begin{array}{c}\text { FE-SMA } \\
\text { MLE }\end{array}$} & \multirow{2}{*}{$\begin{array}{c}\text { RE-SMA } \\
\text { MLE }\end{array}$} & \multirow{2}{*}{$\begin{array}{c}\text { SAR-RE } \\
\text { GM }\end{array}$} & \multirow{2}{*}{$\begin{array}{c}\text { SMA-RE } \\
\text { GM }\end{array}$} \\
\hline & & & & & & & & MLE & GM & & & & MLE & GM & & & & \\
\hline \multirow{4}{*}{ 1st year } & 0.4 & 4 & 3.9843 & 3.9843 & 3.8382 & 3.7875 & 3.9851 & 3.9851 & 3.9382 & 3.8371 & 3.7811 & 3.9858 & 3.9853 & 3.9646 & 3.8372 & 3.7793 & 3.7658 & 3.7748 \\
\hline & & 16 & 3.6053 & 3.6055 & 1.9078 & 1.9063 & 3.6062 & 3.6064 & 3.5985 & 1.9068 & 1.9047 & 3.6062 & 3.6064 & 3.5523 & 1.9068 & 1.9047 & 1.9053 & 1.8890 \\
\hline & 0.8 & 4 & 7.1129 & 7.1136 & 7.2553 & 7.0794 & 7.1079 & 7.0996 & 7.0918 & 7.2510 & 7.0585 & 7.1095 & 7.1052 & 7.0710 & 7.2515 & 7.0284 & 7.0274 & 7.0651 \\
\hline & & 16 & 4.6280 & 4.6280 & 3.5936 & 3.5781 & 4.6288 & 4.6276 & 4.6144 & 3.5912 & 3.5555 & 4.6285 & 4.6285 & 4.6275 & 3.5912 & 3.5636 & 3.6072 & 3.5700 \\
\hline \multirow{4}{*}{ 2nd year } & 0.4 & 4 & 4.3846 & 4.3848 & 4.2351 & 4.1769 & 4.3853 & 4.3854 & 4.3615 & 4.2332 & 4.1700 & 4.3862 & 4.3855 & 4.3940 & 4.2332 & 4.1694 & 4.1758 & 4.1855 \\
\hline & & 16 & 3.8386 & 3.8386 & 2.1195 & 2.1177 & 3.8400 & 3.8400 & 3.8379 & 2.1185 & 2.1161 & 3.8400 & 3.8401 & 3.7906 & 2.1186 & 2.1163 & 2.1200 & 2.1139 \\
\hline & 0.8 & 4 & 7.8694 & 7.8698 & 8.0282 & 7.8327 & 7.8657 & 7.8516 & 7.8364 & 8.0208 & 7.8165 & 7.8670 & 7.8612 & 7.8633 & 8.0211 & 7.7782 & 7.8009 & 7.7973 \\
\hline & & 16 & 5.0879 & 5.0877 & 4.0125 & 3.9963 & 5.0906 & 5.0888 & 5.0560 & 4.0091 & 3.9693 & 5.0907 & 5.0902 & 5.0778 & 4.0092 & 3.9789 & 3.9965 & 3.9857 \\
\hline \multirow{4}{*}{3 rd year } & 0.4 & 4 & 4.5505 & 4.5506 & 4.4045 & 4.3422 & 4.5510 & 4.5512 & 4.5436 & 4.4023 & 4.3345 & 4.5518 & 4.5513 & 4.5538 & 4.4023 & 4.3349 & 4.3386 & 4.3471 \\
\hline & & 16 & 3.9260 & 3.9261 & 2.2016 & 2.1996 & 3.9269 & 3.9270 & 3.9281 & 2.2007 & 2.1984 & 3.9270 & 3.9272 & 3.8853 & 2.2008 & 2.1985 & 2.2016 & 2.1962 \\
\hline & 0.8 & 4 & 8.1983 & 8.1986 & 8.3547 & 8.1578 & 8.1953 & 8.1803 & 8.1728 & 8.3467 & 8.1401 & 8.1968 & 8.1916 & 8.1733 & 8.3468 & 8.1020 & 8.1314 & 8.0947 \\
\hline & & 16 & 5.2566 & 5.2564 & 4.1800 & 4.1625 & 5.2589 & 5.2569 & 5.2433 & 4.1764 & 4.1337 & 5.2589 & 5.2583 & 5.2468 & 4.1765 & 4.1442 & 4.1660 & 4.1409 \\
\hline \multirow{4}{*}{ 4th year } & 0.4 & 4 & 4.6440 & 4.6441 & 4.4982 & 4.4345 & 4.6446 & 4.6447 & 4.6292 & 4.4962 & 4.4266 & 4.6452 & 4.6449 & 4.6391 & 4.4963 & 4.4275 & 4.4165 & 4.4388 \\
\hline & & 16 & 3.9691 & 3.9692 & 2.2455 & 2.2435 & 3.9699 & 3.9700 & 3.9702 & 2.2447 & 2.2422 & 3.9700 & 3.9703 & 3.9296 & 2.2447 & 2.2423 & 2.2405 & 2.2421 \\
\hline & 0.8 & 4 & 8.3769 & 8.3771 & 8.5328 & 8.3333 & 8.3737 & 8.3591 & 8.3368 & 8.5245 & 8.3186 & 8.3752 & 8.3709 & 8.3320 & 8.5247 & 8.2773 & 8.2932 & 8.2741 \\
\hline & & 16 & 5.3387 & 5.3386 & 4.2529 & 4.2362 & 5.3417 & 5.3396 & 5.3215 & 4.2493 & 4.2083 & 5.3417 & 5.3410 & 5.3354 & 4.2496 & 4.2180 & 4.2461 & 4.2309 \\
\hline \multirow{4}{*}{5 th year } & 0.4 & 4 & 4.6925 & 4.6926 & 4.5465 & 4.4825 & 4.6933 & 4.6933 & 4.6871 & 4.5444 & 4.4746 & 4.6940 & 4.6935 & 4.6986 & 4.5444 & 4.4754 & 4.4726 & 4.4953 \\
\hline & & 16 & 3.9955 & 3.9957 & 2.2725 & 2.2704 & 3.9963 & 3.9964 & 3.9971 & 2.2717 & 2.2692 & 3.9964 & 3.9966 & 3.9525 & 2.2718 & 2.2693 & 2.2666 & 2.2691 \\
\hline & 0.8 & 4 & 8.4803 & 8.4805 & 8.6351 & 8.4361 & 8.4766 & 8.4619 & 8.4395 & 8.6269 & 8.4259 & 8.4780 & 8.4740 & 8.4222 & 8.6272 & 8.3795 & 8.4074 & 8.3813 \\
\hline & & 16 & 5.3877 & 5.3876 & 4.2969 & 4.2799 & 5.3903 & 5.3883 & 5.3718 & 4.2931 & 4.2520 & 5.3903 & 5.3897 & 5.3847 & 4.2933 & 4.2615 & 4.2954 & 4.2892 \\
\hline \multirow{4}{*}{ Average } & 0.4 & 4 & 4.4512 & 4.4513 & 4.3045 & 4.2447 & 4.4519 & 4.4519 & 4.4319 & 4.3026 & 4.2374 & 4.4526 & 4.4521 & 4.4500 & 4.3027 & 4.2373 & 4.2339 & 4.2483 \\
\hline & & 16 & 3.8669 & 3.8670 & 2.1494 & 2.1475 & 3.8679 & 3.8680 & 3.8664 & 2.1485 & 2.1461 & 3.8679 & 3.8681 & 3.8221 & 2.1485 & 2.1462 & 2.1468 & 2.1421 \\
\hline & 0.8 & 4 & 8.0075 & 8.0079 & 8.1612 & 7.9679 & 8.0038 & 7.9905 & 7.9755 & 8.1540 & 7.9519 & 8.0053 & 8.0006 & 7.9723 & 8.1543 & 7.9131 & 7.9321 & 7.9225 \\
\hline & & 16 & 5.1398 & 5.1397 & 4.0672 & 4.0506 & 5.1421 & 5.1403 & 5.1214 & 4.0638 & 4.0237 & 5.1420 & 5.1415 & 5.1344 & 4.0640 & 4.0333 & 4.0622 & 4.0434 \\
\hline
\end{tabular}


Table 14 - Forecasts RMSE - $(\mathrm{N}, \mathrm{T})=(\mathbf{5 0 , 1 0 )}$, SMA data generating process for $\phi, W(1,1), 1000$ replications under non-normality of individual effects

\begin{tabular}{|c|c|c|c|c|c|c|c|c|c|c|c|c|c|c|c|c|c|c|}
\hline & \multicolumn{18}{|c|}{ Estimators } \\
\hline & \multirow[b]{2}{*}{$\rho$} & \multirow[b]{2}{*}{$\sigma_{\mu}^{2}$} & \multirow{2}{*}{$\begin{array}{l}\text { Pooled } \\
\text { OLS }\end{array}$} & \multirow{2}{*}{$\begin{array}{c}\text { Av. hetero. } \\
\text { OLS }\end{array}$} & \multirow{2}{*}{ FE } & \multirow{2}{*}{ RE } & \multirow{2}{*}{$\begin{array}{c}\text { Pooled SAR } \\
\text { MLE }\end{array}$} & \multicolumn{2}{|c|}{ Av. hetero. SAR } & \multirow{2}{*}{$\begin{array}{c}\text { FE-SAR } \\
\text { MLE }\end{array}$} & \multirow{2}{*}{$\begin{array}{c}\text { RE-SAR } \\
\text { MLE }\end{array}$} & \multirow{2}{*}{$\begin{array}{c}\text { Pooled SMA } \\
\text { MLE }\end{array}$} & \multicolumn{2}{|c|}{ Av. hetero. SMA } & \multirow{2}{*}{$\begin{array}{c}\text { FE-SMA } \\
\text { MLE }\end{array}$} & \multirow{2}{*}{$\begin{array}{c}\text { RE-SMA } \\
\text { MLE }\end{array}$} & \multirow{2}{*}{$\begin{array}{c}\text { SAR-RE } \\
\text { GM }\end{array}$} & \multirow{2}{*}{$\begin{array}{c}\text { SMA-RE } \\
\text { GM }\end{array}$} \\
\hline & & & & & & & & MLE & GM & & & & MLE & GM & & & & \\
\hline \multirow{4}{*}{ 1st year } & 0.4 & 4 & 3.6733 & 3.6734 & 3.4998 & 3.4549 & 3.6746 & 3.6745 & 3.6271 & 3.4987 & 3.4473 & 3.6748 & 3.6750 & 3.6574 & 3.4986 & 3.4485 & 3.4357 & 3.4539 \\
\hline & & 16 & 3.4929 & 3.4932 & 1.7556 & 1.7525 & 3.4940 & 3.4941 & 3.4804 & 1.7551 & 1.7510 & 3.4939 & 3.4940 & 3.4827 & 1.7550 & 1.7511 & 1.7336 & 1.7350 \\
\hline & 0.8 & 4 & 3.9969 & 3.9972 & 3.8617 & 3.8078 & 3.9973 & 3.9966 & 3.9817 & 3.8584 & 3.7885 & 3.9997 & 3.9992 & 3.9887 & 3.8579 & 3.7860 & 3.7983 & 3.8020 \\
\hline & & 16 & 3.5497 & 3.5495 & 1.9274 & 1.9242 & 3.5524 & 3.5514 & 3.5657 & 1.9249 & 1.9203 & 3.5522 & 3.5516 & 3.5819 & 1.9244 & 1.9192 & 1.9219 & 1.9204 \\
\hline \multirow{4}{*}{ 2nd year } & 0.4 & 4 & 4.0535 & 4.0534 & 3.8677 & 3.8189 & 4.0541 & 4.0540 & 4.0285 & 3.8663 & 3.8117 & 4.0545 & 4.0544 & 4.0544 & 3.8662 & 3.8127 & 3.8111 & 3.8231 \\
\hline & & 16 & 3.7113 & 3.7116 & 1.9382 & 1.9358 & 3.7119 & 3.7121 & 3.7025 & 1.9375 & 1.9344 & 3.7118 & 3.7121 & 3.7042 & 1.9375 & 1.9345 & 1.9271 & 1.9294 \\
\hline & 0.8 & 4 & 4.4167 & 4.4168 & 4.2835 & 4.2212 & 4.4170 & 4.4164 & 4.3894 & 4.2799 & 4.1969 & 4.4194 & 4.4188 & 4.4118 & 4.2792 & 4.1940 & 4.2167 & 4.2318 \\
\hline & & 16 & 3.7920 & 3.7921 & 2.1416 & 2.1385 & 3.7944 & 3.7939 & 3.8054 & 2.1394 & 2.1354 & 3.7942 & 3.7940 & 3.8197 & 2.1391 & 2.1343 & 2.1341 & 2.1358 \\
\hline \multirow{4}{*}{ 3rd year } & 0.4 & 4 & 4.2007 & 4.2007 & 4.0168 & 3.9653 & 4.2009 & 4.2010 & 4.1888 & 4.0154 & 3.9581 & 4.2012 & 4.2013 & 4.2063 & 4.0153 & 3.9594 & 3.9635 & 3.9718 \\
\hline & & 16 & 3.7873 & 3.7876 & 2.0075 & 2.0051 & 3.7879 & 3.7883 & 3.7774 & 2.0067 & 2.0037 & 3.7879 & 3.7883 & 3.7772 & 2.0067 & 2.0038 & 2.0066 & 2.0078 \\
\hline & 0.8 & 4 & 4.5866 & 4.5866 & 4.4500 & 4.3852 & 4.5876 & 4.5866 & 4.5760 & 4.4459 & 4.3620 & 4.5895 & 4.5891 & 4.5831 & 4.4454 & 4.3584 & 4.3836 & 4.3842 \\
\hline & & 16 & 3.8824 & 3.8826 & 2.2276 & 2.2245 & 3.8841 & 3.8836 & 3.8915 & 2.2251 & 2.2213 & 3.8837 & 3.8838 & 3.9154 & 2.2249 & 2.2202 & 2.2155 & 2.2156 \\
\hline \multirow{4}{*}{ 4th year } & 0.4 & 4 & 4.2871 & 4.2872 & 4.1026 & 4.0499 & 4.2877 & 4.2878 & 4.2745 & 4.1012 & 4.0429 & 4.2879 & 4.2881 & 4.2814 & 4.1010 & 4.0440 & 4.0378 & 4.0524 \\
\hline & & 16 & 3.8243 & 3.8246 & 2.0460 & 2.0434 & 3.8246 & 3.8249 & 3.8150 & 2.0452 & 2.0420 & 3.8246 & 3.8250 & 3.8178 & 2.0452 & 2.0421 & 2.0451 & 2.0480 \\
\hline & 0.8 & 4 & 4.6830 & 4.6830 & 4.5438 & 4.4782 & 4.6831 & 4.6822 & 4.6643 & 4.5391 & 4.4548 & 4.6849 & 4.6846 & 4.6652 & 4.5384 & 4.4507 & 4.4714 & 4.4656 \\
\hline & & 16 & 3.9245 & 3.9247 & 2.2678 & 2.2647 & 3.9262 & 3.9258 & 3.9301 & 2.2654 & 2.2615 & 3.9258 & 3.9259 & 3.9626 & 2.2650 & 2.2602 & 2.2625 & 2.2616 \\
\hline \multirow{4}{*}{ 5th year } & 0.4 & 4 & 4.3336 & 4.3337 & 4.1502 & 4.0964 & 4.3340 & 4.3341 & 4.3277 & 4.1489 & 4.0897 & 4.3343 & 4.3345 & 4.3378 & 4.1488 & 4.0908 & 4.0843 & 4.0988 \\
\hline & & 16 & 3.8487 & 3.8489 & 2.0716 & 2.0691 & 3.8490 & 3.8493 & 3.8374 & 2.0710 & 2.0677 & 3.8489 & 3.8493 & 3.8416 & 2.0710 & 2.0678 & 2.0739 & 2.0698 \\
\hline & 0.8 & 4 & 4.7412 & 4.7413 & 4.6001 & 4.5343 & 4.7420 & 4.7408 & 4.7269 & 4.5957 & 4.5119 & 4.7436 & 4.7434 & 4.7220 & 4.5950 & 4.5073 & 4.5249 & 4.5125 \\
\hline & & 16 & 3.9535 & 3.9537 & 2.2953 & 2.2922 & 3.9548 & 3.9545 & 3.9573 & 2.2928 & 2.2887 & 3.9545 & 3.9546 & 3.9903 & 2.2923 & 2.2874 & 2.2895 & 2.2925 \\
\hline \multirow{4}{*}{ Average } & 0.4 & 4 & 4.1096 & 4.1097 & 3.9274 & 3.8771 & 4.1103 & 4.1103 & 4.0893 & 3.9261 & 3.8699 & 4.1106 & 4.1107 & 4.1075 & 3.9260 & 3.8711 & 3.8665 & 3.8800 \\
\hline & & 16 & 3.7329 & 3.7332 & 1.9638 & 1.9612 & 3.7335 & 3.7337 & 3.7225 & 1.9631 & 1.9597 & 3.7334 & 3.7338 & 3.7247 & 1.9631 & 1.9598 & 1.9572 & 1.9580 \\
\hline & 0.8 & 4 & 4.4849 & 4.4850 & 4.3478 & 4.2853 & 4.4854 & 4.4845 & 4.4677 & 4.3438 & 4.2628 & 4.4874 & 4.4870 & 4.4742 & 4.3432 & 4.2593 & 4.2790 & 4.2792 \\
\hline & & 16 & 3.8204 & 3.8205 & 2.1719 & 2.1688 & 3.8224 & 3.8218 & 3.8300 & 2.1695 & 2.1654 & 3.8221 & 3.8220 & 3.8540 & 2.1692 & 2.1643 & 2.1647 & 2.1652 \\
\hline
\end{tabular}

